Infectious Diseases

Elsevier Editorial system(tm) for The Lancet Manuscript Draft

Manuscript Number: THELANCETID-D-17-00064R1

Title: The timing of surgical antimicrobial prophylaxis: a randomised controlled trial

Article Type: Articles (Original Research)

Keywords: Surgical Site Infection

Surgical Antimicrobial Prophylaxis

Corresponding Author: Professor Walter Paul Weber, M.D.

Corresponding Author's Institution: University Hospital Basel

First Author: Walter Paul Weber, M.D.

Order of Authors: Walter Paul Weber, M.D.; Edin Mujagic, MD; Marcel Zwahlen, PhD; Marcel Bundi, MD; Henry Hoffmann, MD; Savas D Soysal, MD; Marko Kraljević, MD; Tarik Delko, MD; Marco von Strauss, MD; Lukas Iselin, MD; Richard X Sousa Da Silva, MD; Jasmin Zeindler, MD; Rachel Rosenthal, MD; Heidi Misteli, MD; Christoph Kindler, MD; Peter Müller, MD; Ramon Saccilotto, MD; Andrea Kopp Lugli, MD; Mark Kaufmann, MD; Lorenz Gürke, MD; Daniel Oertli, MD; Evelin Bucheli-Laffer, MD; Julia Landin, MD; Andreas F Widmer, MD; Christoph A Fux, MD; Walter R Marti, MD

Manuscript Region of Origin: SWITZERLAND

Abstract: Background

Administration of surgical antimicrobial prophylaxis (SAP) for the prevention of surgical site infection (SSI) is recommended within 60 minutes before incision based on observational studies. However, the precise optimal timing is unknown. This trial compared early versus late administration before surgery.

Methods

In this randomised controlled phase III superiority trial, we included general surgery adult inpatients (age $\geq 18$ years) at two Swiss hospitals. Patients were randomised centrally and stratified by hospital according to a pre-existing computer-generated list in a 1:1 ratio to receive SAP early in the anaesthesia room versus late in the operating room. Patients and the outcome assessment team were masked to group assignment. SAP consisted of single-shot, intravenous infusion of $1.5 \mathrm{~g}$ of cefuroxime, a commonly used cephalosporin with a short half-life, over 2-5 minutes (combined with $500 \mathrm{mg}$ metronidazole in colorectal surgery). The primary endpoint was the occurrence of SSI within 30 days of surgery. The main analyses were intention-to-treat. The study is registered with ClinicalTrials.gov, number NCT01790529.

Findings

Between February 21, 2013, and August 3, 2015, 5580 patients were randomly assigned to receive SAP early (2798 patients) or late (2782 patients), of whom 5175 (2589 early and 2586 late) were analysed. Median administration time was 42 minutes before incision in the early group (interquartile range [IQR] 30-55 minutes) and 16 minutes before incision in the late group (IQR 10-25 minutes). Inpatient follow-up rate was 100\% 
(5175/5175); outpatient 30-day follow-up rate was $88 \cdot 8 \%$ (4596/5175), with an overall SSI rate of 5.1\% (234 of 4596). Early administration of SAP did not significantly reduce the risk of SSI compared to late administration (odds ratio $=0.93$; 95\% confidence interval, 0.72 to $1 \cdot 21$; $\mathrm{p}=0 \cdot 601)$.

Interpretation

The present results do not support any narrowing of the 60-minute time window for the administration of a cephalosporin with a short half-life. Funding

Swiss National Science Foundation, Hospital of Aarau, University of Basel, Gottfried und Julia Bangerter-Rhyner Foundation, Hippocrate Foundation, Nora van Meeuwen-Häfliger Foundation. 


\section{The timing of surgical antimicrobial prophylaxis: a randomised controlled trial}

Walter P. Weber ${ }^{*}$ Edin Mujagic ${ }^{\star}$, Marcel Zwahlen, Marcel Bundi, Henry Hoffmann, Savas D. Soysal, Marko Kraljević, Tarik Delko, Marco von Strauss, Lukas Iselin, Richard X. Sousa Da Silva, Jasmin Zeindler, Rachel Rosenthal, Heidi Misteli, Christoph Kindler, Peter Müller, Ramon Saccilotto, Andrea Kopp Lugli, Mark Kaufmann, Lorenz Gürke, Daniel Oertli, Evelin Bucheli-Laffer, Julia Landin, Andreas F. Widmer, Christoph A. Fux, Walter R. Marti

*The first two authors contributed equally to this work

Department of General Surgery, University Hospital Basel, Basel, Switzerland (Prof W Weber MD, E Mujagic MD, H Hoffmann MD, S Soysal MD, M Kraljević MD, T Delko MD, M von Strauss MD, L Iselin MD, J Zeindler MD, H Misteli MD, Prof L Gürke MD, Prof D Oertli MD, J Landin MD);

University of Basel, Basel, Switzerland (Prof W Weber MD, E Mujagic MD, H Hoffmann MD, S Soysal MD, M Kraljević MD, T Delko MD, M von Strauss MD, L Iselin MD, J Zeindler MD, Prof R Rosenthal MD, H Misteli MD, R Saccilotto MD, A Kopp Lugli MD, Prof M Kaufmann $M D$, Prof $L$ Gürke MD, Prof D Oertli MD, J Landin MD, Prof A Widmer MD);

Institute of Social and Preventive Medicine, University of Bern, Bern, Switzerland (Prof Marcel Zwahlen PhD);

Department of General Surgery, Hospital of Aarau, Aarau, Switzerland (M Bundi MD, M von Strauss MD, R. Sousa Da Silva MD, Prof W Marti MD);

Department of Anaesthesiology, Hospital of Aarau, Aarau, Switzerland (Prof C Kindler MD, P Müller MD);

Department of Infectious Diseases, Hospital of Aarau, Aarau, Switzerland (E Bucheli-Laffer MD, C Fux MD)

Department of Anaesthesiology, University Hospital Basel, Basel, Switzerland (A Kopp Lugli MD, Prof M Kaufmann MD);

Division of Infectious Diseases and Hospital Epidemiology, University Hospital Basel, Basel, Switzerland (Prof A Widmer MD); and

Department of Clinical Research, University Hospital Basel, Basel, Switzerland (R Saccilotto MD)

Correspondence to:

Prof Walter P Weber, Department of General Surgery, University Hospital Basel, Basel, 4031, Switzerland

walter.weber@usb.ch 


\section{Summary}

\section{Background}

Administration of surgical antimicrobial prophylaxis (SAP) for the prevention of surgical site infection (SSI) is recommended within 60 minutes before incision based on observational studies. However, the precise optimal timing is unknown. This trial compared early versus late administration before surgery.

\section{Methods}

In this randomised controlled phase III superiority trial, we included general surgery adult inpatients (age $\geq 18$ years) at two Swiss hospitals. Patients were randomised centrally and stratified by hospital according to a pre-existing computer-generated list in a 1:1 ratio to receive SAP early in the anaesthesia room versus late in the operating room. Patients and the outcome assessment team were masked to group assignment. SAP consisted of singleshot, intravenous infusion of $1.5 \mathrm{~g}$ of cefuroxime, a commonly used cephalosporin with a short half-life, over 2-5 minutes (combined with 500 mg metronidazole in colorectal surgery). The primary endpoint was the occurrence of SSI within 30 days of surgery. The main analyses were intention-to-treat. The study is registered with ClinicalTrials.gov, number NCT01790529.

\section{Findings}

Between February 21, 2013, and August 3, 2015, 5580 patients were randomly assigned to receive SAP early (2798 patients) or late (2782 patients), of whom 5175 (2589 early and 2586 late) were analysed. Median administration time was 42 minutes before incision in the early group (interquartile range [IQR] 30-55 minutes) and 16 minutes before incision in the late group (IQR 10-25 minutes). Inpatient follow-up rate was 100\% (5175/5175); outpatient 30-day follow-up rate was $88 \cdot 8 \%(4596 / 5175)$, with an overall SSI rate of $5 \cdot 1 \%$ (234 of 4596). Early administration of SAP did not significantly reduce the risk of SSI compared to late administration (odds ratio $=0.93 ; 95 \%$ confidence interval, 0.72 to $1.21 ; p=0.601$ ).

\section{Interpretation}


The present results do not support any narrowing of the 60-minute time window for the administration of a cephalosporin with a short half-life.

\section{Funding}

Swiss National Science Foundation, Hospital of Aarau, University of Basel, Gottfried und Julia Bangerter-Rhyner Foundation, Hippocrate Foundation, Nora van Meeuwen-Häfliger Foundation. 


\section{Background}

Surgical Site Infections (SSI) are the most common hospital-acquired infections among surgical patients with substantial economic impact.(1) Administration of surgical antimicrobial prophylaxis (SAP) is a highly effective method to reduce the risk of SSI after various procedures.(2-4) Single shot first- or second-generation cephalosporins are widely used as agents of choice for routine SAP, supplemented with metronidazole to provide anaerobic activity in colorectal surgery.(5)

The association of timing of SAP and risk of SSI has been described early in experimental animal studies.(6) The landmark study by Classen et al in 1992 showed the lowest risk of SSI in humans when SAP was initiated within two hours prior to skin incision.(7) The 2016 World Health Organization (WHO) guidelines for the prevention of SSI still call for a timing of less than 120 min before incision, but recommend that administration should be closer to the incision time ( $<60$ minutes before) for antibiotics with a short half-life, such as commonly used cephalosporins and penicillins.(8) This 60-minute window before surgery reflects the most widely implemented recommendation on SAP timing.(5;9;10) The 2013 National Institute for Health and Care Excellence guidelines simply recommend a single dose of antibiotic intravenously on starting anaesthesia.(11)

Several groups have attempted to further refine the 60 -minute time window, resulting in two opposing clinical trends in SAP timing recommendations. Most of these observational studies favour the administration shortly before incision.(12-14) Therefore, some guidelines suggest that SAP should be administered within the final 30 minutes before incision, except for vancomycin and the fluoroquinolones. $(15 ; 16)$ Other observational studies suggested that administration close to the incision time may be too late for optimal SSI prevention, including the largest prospective cohort study on cefuroxime (a second generation cephalosporin) to date. $(17 ; 18)$

Based on the available evidence, the joint guidelines from four large American societies concluded that the data are not sufficiently robust to recommend narrowing the 60 -minute 
window.(9) This research gap has been identified by the 2016 WHO guidelines, which call for a randomised controlled trial $(\mathrm{RCT})$ to clarify the optimal timing of SAP as a matter of high priority.(19) Such a trial has the potential to have an important impact on current international guidelines for infection control strategies and to be of significant interest in terms of patient safety and healthcare economics. This RCT was designed to test the hypothesis that early administration of cefuroxime would be superior to late administration before incision for the prevention of SSI, thereby aiming at confirming the results of the observational study on cefuroxime.(18) 


\section{Methods}

Study design

This phase III superiority RCT was conducted at the University Hospital Basel and the Hospital of Aarau, two tertiary care referral centres in Switzerland. The trial including all respective documents was approved by the local ethics committees by April 2012 (Basel: Ref. Nr. EK 19/12; Aarau: Ref. Nr. EK 2011/037). Insurance coverage of general liability has been obtained by both study centres. The study protocol has been published in an open-access journal (https://www.ncbi.nlm.nih.gov/pubmed/24885132) (20).

\section{Patients}

Written informed consent was obtained from all patients. Included patients were $\geq 18$ years of age and underwent inpatient general surgery procedures, specifically gastrointestinal, hernia, endocrine and breast surgery, as well as orthopaedic trauma and vascular procedures with SAP indicated according to international guidelines.(21) Patients were excluded in case of pre-existing antibiotic therapy within 14 days of surgery and in case of emergency procedures with planned incision within 2 hours after registration. A detailed list and explanation of all in- and exclusion criteria is provided in the supplementary appendix 1.

Randomisation and masking

Randomisation was stratified by study site and performed centrally at the day of surgery according to a pre-existing computer-generated list, which was provided by a statistician who was not involved in screening patients or assessing outcomes. For the purpose of communication of treatment allocation to the anaesthesia team, the randomisation list was linked with the clinical data system (developed by ProtecData AG, Boswil, Switzerland). In order to see the result of randomisation, the members of the anaesthesia team had to log into the clinical data system and press a button with a time stamp. This button was a mandatory item to print their routine preoperative evaluation sheet with the treatment plan on the day of surgery. It only appeared if a patient was included in the study. The result was 
then presented for that specific patient and procedure on screen and was included in the printed sheet. At no time did the anaesthesiologists or anaesthesia nurses have access to the randomisation list. Patients were screened, consented and enrolled by investigators who were part of the surgical team performing the procedure and who were not involved in assessing outcomes for the purpose of the study. Patients and the outcome assessment team were masked to group assignment.

Patients were randomly assigned in a 1:1 ratio to receive SAP in the anaesthesia room, which was located in front of the actual operating room (arm A) versus in the operating room itself (arm B). We estimated that patients in arm A would receive SAP early, approximately 75 - 30 minutes before the scheduled incision, which reflects the time window with the lowest rates of SSI in the prospective observational cohort study on cefuroxime.(18) We estimated that patients in arm B would receive SAP late, approximately $<30-0$ minutes before the scheduled incision.

\section{Procedures}

SAP was administered by the anaesthesia team to all patients in a standardised manner via single-shot, intravenous infusion of $1.5 \mathrm{~g}$ of cefuroxime (Glaxo Smith Kline, Verona, Italy) in $100 \mathrm{ml}$ of a $0.9 \%$ sodium chloride solution over $2-5$ minutes. It was combined with metronidazole (500 mg, intravenous infusion, 2-5 minutes, B. Braun, Rubì, Spain) in colorectal surgery patients, who received no bowel preparation with non-absorbable intraluminal antibiotics. In case of a body-weight equal to or above $80 \mathrm{~kg}$, the doses were doubled ( $3 \mathrm{~g}$ of cefuroxime, $1 \mathrm{~g}$ of metronidazole). The exact time in minutes that the infusion started was recorded by the anaesthesiologist or anaesthesia nurse. The same dose of cefuroxime (plus the same dose of metronidazole in colorectal surgery) was given every four hours after the first administration. In patients with impaired renal function, this re-dose was adapted according to the creatinine clearance. 
The primary endpoint was the occurrence of any SSI within 30 days after surgery. SSI was defined as incisional (either superficial or deep) or organ/space infection according to the Centers for Disease Control and Prevention (CDC) criteria that were published in 1999.(21) These definitions required a surveillance period of 30 days, which was extended to one year in case of implant surgery. During the conduct of the study, the CDC National Healthcare Safety Network (NHSN) updates called for a change to follow up duration for several procedures included in this trial. Follow up was shortened from twelve to three months for implant-based surgery, extended from one to three months for breast surgery, herniorrhaphy and peripheral bypass surgery even when using autologous tissue, and remained unchanged (one month) for the rest of the procedures in this trial.(22) Therefore, we decided on July 30 , 2015 , to homogenise the duration of follow up for all procedures to one month as this was pre-specified for all procedures in this study, and to abandon the additional follow up one year after surgery in case of implants.

The surgical team followed the patients by routine wound surveillance according to clinical standards including diagnosis and treatment of SSI. The physicians of the ward who were in charge of inpatient care were masked to the intervention and were responsible for the assessment of SSI for the purpose of this study, which was continuously cross-checked by supervising members of the masked wound surveillance study team. In addition, the masked members of the outcome assessment team participated daily in the hospital rounds together with the surgical team and the physicians of the ward and visited patients directly in case of potential events. For post-discharge follow-up, trained nurses and clinicians at each study site who were masked to group assignment contacted all patients 30 days after surgery by telephone. The past or present occurrence of SSI was assessed by a standardised questionnaire, and the physician who performed post-surgery outpatient clinical controls was identified. Whenever the telephone assessment suggested a possible event, primary care physicians were contacted for detailed information from their charts, and the hospital charts were reviewed as well. After five unsuccessful attempts to contact patients within a period of 
4 weeks after the 30 day follow-up, in-hospital charts were screened for readmissions and surgical take-backs. All cases showing evidence of SSI were validated by a board certified infectious diseases specialist at each study site who was masked to group assignment. Prespecified secondary endpoints included all-cause 30-day mortality and length of hospital stay.

The study was conducted in compliance with the protocol and according to Good Clinical Practice standards, as well as legal regulations. However, in accordance with the local ethics committees, only serious adverse events (SAE) were reported to the sponsor. These included death from any cause, life threatening SAE, SAE that caused a prolongation of the length of hospital stay, SAE that caused a persistent and significant handicap to the patient and SAE that required an intervention in order to prevent one or several of the above mentioned. Deaths were additionally reported to the local ethics committees within 7 days of becoming apparent to the study team. SSI were not reported as SAE since they correspond to the endpoint of this study.

\section{Statistical Analysis}

The target enrolment was 5000 evaluable patients for a 1:1 ratio randomisation to have SAP administered early in the anaesthesia room (arm A) or late in the operating room (arm B). Instead of arbitrarily defining a minimal important reduction of the risk of SSI that would call for a shortening of the currently recommended time window for the administration of SAP, the assumptions for the sample size calculations were derived from the results of the observational study conducted in the years 2000-2001 at the University Hospital Basel.(18) We assumed that administration of SAP early in the anaesthesia room would result in a $33 \%$ relative reduction of SSI risk and that the SSI risk with SAP administration in the operating room would be $5 \%$. Together with a power of $80 \%$ and a two-sided type I error of $5 \%$ these assumptions resulted in two groups of 2500 patients each.

The main analyses were intention-to-treat, which provides a valid estimate of comparing a policy to administer SAP early in the anaesthesia room versus a policy to administer SAP 
late in the operating room. For the binary endpoints 30-day SSI and 30-day all-cause mortality, we present complete case analyses including patients with complete 30-day followup. Even though all patients were completely followed during the hospital stay, not all patients could be contacted after discharge to ascertain SSI and vital status at day 30 (see figure 1). To assess robustness of the complete case analyses, we also performed all analyses of the 30-day binary outcomes using inverse probability of censoring weights (IPCW).(23;24) IPCW account for the possibility that the likelihood of having obtained followup information might vary and might depend on risk factors of SSI and mortality (see supplementary appendix 2 for simplified arguments for using IPCW). IPCW were derived from a logistic regression with availability of follow-up information as the outcome including predictors related to surgery (wound class, surgical division, duration of surgery, emergency surgery) and related to the patient (ASA score, number of comorbidities, having diabetes, body mass index above 30 , being older than 65 , taking immunosuppressive drugs and smoking status). We calculated absolute risks of SSI or mortality and used logistic regression to obtain the odds ratio and $95 \%$ confidence intervals for comparing patients by randomisation group. Robust standard errors were used in the IPCW analyses. For the comparison of length of hospital stay (available for all patients), we used the two-sample Wilcoxon (Mann-Whitney) rank-sum test.

In addition to the intention-to-treat analysis, which evaluates the difference between the two policies of administering SAP, we performed an "as treated" and a "per protocol" analysis for the primary outcome of any SSI within 30 days after surgery.(25) As both of these analyses are prone to being biased due to imbalances in prognostic factors, multivariable logistic regression models were used including hospital, wound class, surgical division, duration of surgery, emergency surgery, ASA score, number of comorbidities, having diabetes, body mass index above 30 , being older than 65 , taking immunosuppressive drugs and smoking status in addition to the main variable of where SAP was received. These additional analyses were post hoc and not defined in the study protocol.(20) 
We conducted three pre-specified subgroup analyses: age ( $\geq 65$ versus $<65$ years), body mass index ( $\geq 30$ versus $<30 \mathrm{~kg} / \mathrm{m} 2$ ) and diabetes (with versus without). Three subgroup analyses were post hoc: Surgical division (visceral versus trauma versus vascular), presence versus absence of immunosuppressive drugs and wound class (I versus II versus III versus IV). For these analyses we included interaction terms between randomisation group and the respective subgroups to obtain Wald-type interaction $p$-values. We provide descriptive statistics for the exact SAP timing by randomisation group. All analyses were done using $\mathrm{R}$ and Stata $14 \cdot 1$ (Stata Corp, Texas).

The clinical trial unit of the University Hospital Basel oversaw the study at both sites and provided continuous central and on-site monitoring. One pre-specified interim analysis was performed according to the study protocol after having recruited and operated on 2500 patients. Decisions for stopping were done using a fully probabilistic approach; they were pre-specified in the protocol and strictly followed after the results of the interim analysis became available.(20;26) The obtained predictive probability was $8.357 \%$ for a significant result at the end of the study. With this interim result, the study neither fulfilled the criteria for stopping for futility nor for early success and therefore continued to full length. Due to the interim analysis, which also included a criterion for stopping for superiority, a p-value of $<4.5 \%$ at the final analysis would have been necessary to claim superiority and preserve an overall type I error of $5 \%$.

The trial has been registered on ClinicalTrials.gov (number, NCT01790529).

Role of the funding source

No commercial support was provided for this study. The study was primarily funded by the Swiss National Science Foundation. Additional funding was received from the Hospital of Aarau, the University of Basel, the Gottfried und Julia Bangerter-Rhyner Foundation, the Hippocrate Foundation, and the Nora van Meeuwen-Häfliger Foundation. The funders of the study had no role in study design, data collection, data analysis, data interpretation, or writing 
of the report. The corresponding author had full access to all the data in the study and had final responsibility for the decision to submit for publication. 


\section{Results}

Between February 21, 2013, and August 3, 2015, a total of 8870 patients were assessed for eligibility, 3290 of whom were excluded (1759 due to the presence of at least one exclusion criterion, and 1531 declined to participate, see figure 1). The remaining 5580 patients were randomly assigned to receive SAP early in the anaesthesia room (2798 patients) or late in the operating room (2782 patients.) Of those 5580 randomised patients, 41 (0.7\%) did not undergo surgery, $22(0 \cdot 4 \%)$ were younger than 18 years and $342(6 \cdot 1 \%)$ had an invalid or missing informed consent. These patients were excluded post-randomisation, and the study continued to a total accrual of 5175 patients, 2995 in Basel and 2180 in Aarau, for the primary intention-to-treat analysis (2589 in the early and 2586 in the late group). A small number of patients $(n=64)$ that received SAP before incision and were later categorised as having wound class IV were included in the intention-to-treat analysis.

In the group that was randomised to receive SAP in the anaesthesia room (early group), 336 (13\%) received it in the operating room (late group). In the group that was assigned to receive SAP in the operating room (late group), 363 (14\%) patients received it in the anaesthesia room (early group). Median administration time in the early group was 42 minutes (interquartile range [IQR] 30-55 minutes) and in the late group 16 minutes before incision (IQR 10-25 minutes). In the early group, 16 patients had SAP initiated after incision, while 22 patients did not receive the study drugs. In the late group, 21 patients had SAP initiated after incision and 33 did not receive the study drugs.

All 5175 patients were followed until discharge, while 4596 of these (88.8\%) were successfully followed after 30 days. A similar number of participants in each group were lost to 30 day outpatient follow-up: $293(11.3 \%)$ in the early group and $286(11.1 \%)$ in the late group. Distribution of patient and procedure characteristics for the two groups was similar (table 1).

The overall SSI rate was 5.1\% (234 of 4596) in patients with a complete 30 day follow up, with $113 / 2296 \mathrm{SSI}(4 \cdot 9 \%)$ occurring in the early and $121 / 2300(5 \cdot 3 \%)$ in the late group (see 
table 2). About half of all SSI (120/234) were registered during the hospital stay and half (114/234) after discharge, with no significant difference between the two groups.

Early administration of SAP did not significantly reduce the risk of SSI compared to late administration (odds ratio $=0.93 ; 95 \%$ confidence interval $[95 \% \mathrm{Cl}], 0 \cdot 72$ to $1 \cdot 21 ; \mathrm{p}=0.601$ ). These results were almost identical in the IPCW analysis (odds ratio $=0.93 ; 95 \% \mathrm{Cl}, 0.72$ to $1 \cdot 21 ; p=0.598$, see supplementary appendix 3 ). When repeating the intention-to-treat analysis after exclusion of the 37 patients that had SAP administered after incision and those 55 that had no SAP, the results remained virtually unchanged (odds ratio $=0.93 ; 95 \% \mathrm{Cl}$, $0 \cdot 71-1 \cdot 21 ; p=0.573)$. Similarly, after exclusion of all patients who had an upgrade of their wound class to category IV during surgery, the results remained almost identical (odds ratio $=0 \cdot 94 ; 95 \% \mathrm{Cl}, 0 \cdot 72-1 \cdot 23, \mathrm{p}=0 \cdot 667)$.

The "as treated" analysis included 2567 patients with SAP in the anaesthesia room and 2553 with SAP in the operating room (odds ratio $=0.78 ; 95 \% \mathrm{Cl}, 0.59-1.04 ; \mathrm{p}=0.093$ ). The "per "protocol" analysis included 2231 with SAP in the anaesthesia room and 2190 with SAP in the operating room (odds ratio $=0.86 ; 95 \% \mathrm{Cl}, 0.64-1.17, \mathrm{p}=0.335$ ). Both of these post-hoc analyses showed a more pronounced reduction of the odds of SSI but did also not provide statistically significant evidence favouring early over late administration of SAP. When excluding the 64 patients that were categorised as having wound class IV, those 37 patients that had SAP administered after incision and those 55 that had no SAP, the "as treated" analysis of 4469 patients revealed an odds ratio of $0.80(95 \% \mathrm{Cl}, 0 \cdot 60-1 \cdot 07 ; p=0.135)$. The rates of SSI did not differ between the two groups for all three types of SSI (see table 2). Several pre-specified and post hoc subgroups were examined and provided no evidence for a modification of the effect of early versus late administration of SAP (see figure 2). Since culture or non-culture based testing is not mandatory according to the CDC definitions of SSI, only 73/120 patients with in hospital diagnosis of SSI had pathogens isolated. Table 3 shows the spectrum of pathogens isolated from patients with SSI. Importantly, the presence of multi-resistant pathogens in patients with SSI was extremely low at both study sites. 
There were no significant differences by randomisation group for the secondary endpoints all-cause 30-day mortality and median length of hospital stay (see table 2). 


\section{Discussion}

Panel: Research in context

Evidence before this study

In their 2016 global guidelines for the prevention of surgical site infection (SSI), the World Health Organization provides a strong recommendation based on moderate quality of evidence to administer surgical antimicrobial prophylaxis (SAP) within 120 minutes before incision. They recommend that administration should be closer to the incision time [ $<60$ minutes] for antibiotics with a short half-life, such as commonly used cephalosporins and penicillins. In their summary of evidence, a total of 13 observational studies including 53975 adult patients were included; 2 were from multiple centres. No randomised controlled trials were identified. The guideline development group described this research gap and the need for further studies on this topic, and highlighted the limited evidence available on optimal SAP timing to prevent SSI. They stated that in particular and as a high priority, randomised controlled trials comparing the effect of different time intervals are needed, that is, $60-30$ minutes vs. 30-0 minutes for antibiotics with a short half-life.

The 2013 National Institute for Health and Care Excellence guidelines simply recommend a single dose of antibiotic intravenously on starting anaesthesia. The 2014 Society for Healthcare Epidemiology of America and Infectious Diseases Society of America guidelines recommend administration within 1 hour before incision with superior efficacy between 0 and 30 minutes prior to incision compared with administration between 30 and 60 minutes. Most other international guidelines still recommend administration of SAP within 60 minutes before surgical incision; however, administration within the final 30 minutes is increasingly recommended.

Added value of this study

To the best of our knowledge, this is the first randomised trial examining the effect of different SAP timings on the risk of SSI. It showed that early administration of cefuroxime, a commonly used cephalosporin with a short half-life, combined with metronidazole in colorectal surgery, did not significantly lower the risk of SSI compared to late administration before incision (odds ratio $=0.93$; $95 \%$ confidence interval, 0.72 to $1 \cdot 21 ; p=0 \cdot 601)$.

Implications of all the available evidence

The available evidence to date does not support any narrowing of the 60-minute time window for the routine administration of a cephalosporin with a short half-life. 
To our knowledge, this is the first randomised study examining the effect of different SAP timings on the risk of SSI. The present results showed that early administration of cefuroxime, a commonly used cephalosporin with a short half-life, plus metronidazole in colorectal surgery, did not significantly lower the risk of SSI compared to late administration before incision. Secondary endpoints all-cause 30 day mortality and length of hospital stay also remained unaffected. The study was not underpowered, as the observed SSI rate of $5 \cdot 1 \%$ (234 of 4596$)$ was in agreement with our assumptions for the sample size calculation.(18)

The present RCT addressed two opposing trends in SAP timing recommendations that aim at refining the broad recommendation to administer SAP with a short half-life and infusion time within 60 minutes before surgery. $(5 ; 8-10 ; 19)$ On one side, several guidelines favour late administration of SAP close to the incision time.(15;16;27) The largest observational study examining the relationship between antibiotic timing and SSI risk to date showed a trend toward lowest risk of SSI when SAP with cephalosporins and other antibiotics with short infusion times were given within 30 minutes prior to incision.(13) A second study showed a decreasing rate of infections after total hip arthroplasty in patients who received antibiotics within 30 minutes prior to incision, and a third showed that the lowest rate of infections occurred after various procedures when the antibiotics were given 10 to 20 minutes before incision.(12;14)

On the other side, SAP timing should ensure that tissue drug levels exceed the minimum inhibitory concentration for organisms likely to be present at the surgical site throughout the operation. The hypothesis that administration of antibiotics with a short half-life immediately before incision may be too late for optimal SSI prevention was supported by a prospective pharmacokinetic study that used in vivo microdialysis to measure continuous tissue levels of cefazolin.(28) The authors concluded that cefazolin should be administered at least 60 minutes before skin incision to guarantee for optimal tissue concentration at the beginning of surgery. Vast inter-individual differences were observed for the time required to reach maximum interstitial concentrations. 
In addition, some observational studies suggested that administration of SAP shortly before incision may be too late for optimal SSI prevention. In a combined analysis of data from two small RCTs of single dose piperacillin versus multidose cefoxitin, the lowest rate of infection of $13 \%$ was seen when the drug was given between 16 to 60 minutes before surgery, compared with $21 \%$ when given within 15 minutes before surgery.(17) The authors listed failure to complete preoperative antibiotic infusion prior to the beginning of the operation as the most plausible reason for the high infection rate associated with the late administration of antibiotics.

The largest prospective observational cohort study on cefuroxime analysed the incidence of SSI by the timing of SAP in a series of 3836 consecutive general surgical procedures.(18) In multivariable logistic regression analyses, the odds of SSI were almost doubled when SAP was administered less than 30 minutes as compared to the reference interval of 59 to 30 minutes before incision (adjusted odds ratio $=1 \cdot 95 ; 95 \%$ confidence interval, 1.4 to $2 \cdot 8$; $\mathrm{p}<0.001)$. While SAP was applied in most patients between 44 and 0 minutes before incision, the lowest rate of SSI was recorded when the antibiotics were administered between 74 and 30 minutes before surgery. Based on this study, Swiss guidelines recommend the administration of SAP with cefuroxime (combined with metronidazole in colorectal surgery) 74 to 30 minutes before skin incision.(29) However, corroboration of these findings ideally in a RCT was encouraged by the editorial accompanying the study.(30) The present RCT did not confirm that a policy to administer SAP early in the anaesthesia room would significantly reduce the risk of SSI compared to a policy to administer SAP late in the operating room, and we conclude that the statistical analysis could not reliably adjust for all inherent bias of that prior observational study.

The results from the intention-to-treat analysis with an odds ratio of 0.93 and a $95 \% \mathrm{Cl}$ of 0.72 to 1.21 for early versus late administration of SAP before surgery do not support any narrowing of the 60-minute time window. This is clinically relevant, since the timing of SAP is widely used as a quality criterion in surgical infection prevention projects.(5;10) Many centres 
have problems initiating the infusion within 60 minutes before surgery, and narrowing this window, as recommended by several guidelines, would make this target even more difficult.(15;16;29) Timing difficulties even occurred in the controlled setting of this RCT, with $13.5 \%$ of patients not receiving the assigned intervention.

\section{Limitations}

Our study is not without limitations; the first refers to the generalisability of the findings. The results obtained by the regimen in this study may not be generalisable to other antimicrobial agents with different pharmacokinetics. The trial was performed at two tertiary referral centres in Switzerland, and the results may not be applicable to a differing patient population, such as one with a considerably higher rate of infection or a higher incidence of antimicrobial resistance. The higher dose of SAP administered to patients with a body weight above 80 kilograms may have changed the pharmacokinetics in this subgroup compared to the dose administered to the rest of the study population. Subgroup analyses suggested a consistent absence of superiority of early versus late administration of SAP across subgroups, which increases the generalisability of our findings. However, given that the underlying SSI rate was only $5 \cdot 1 \%$, and the study was powered at $80 \%$ to detect a large treatment effect (33\% relative reduction of SSI risk), we need to acknowledge that the study was only powered to detect large interactions at the subgroup level.

Secondly, even though patients were not informed about assignments to treatment groups, we cannot exclude that some in the early group may have seen the infusion of SAP in case of its administration before induction of anaesthesia. Thirdly, the follow up period of one month is insufficient to detect all SSI after implant based surgery, and outpatient follow up rate at one month was only $88 \cdot 8 \%$ (4596/5175 patients). We decided to follow patients personally by telephone based on our experience with the prior observational study.(18) We restricted the number of attempts to contact patients to five times within a period of 4 weeks after the 30 days follow-up to ensure that the patients remembered any potential event. We do not think, however, that missing follow up data weaken the interpretation of the findings. 
We followed all patients during their hospital stay, and the number of patients lost to outpatient follow-up was equally distributed between the two randomisation groups. We assessed the robustness of the complete case analysis with regard to possible informative loss-to-follow-up by conducting analyses using IPCW in which we obtained very similar results. Fourthly, 342 patients were excluded post-randomisation due to invalid or missing informed consents. The underlying mechanism for the high rate of missing consents was identified and corrected during the course of the study. In brief, it proved to be difficult to collect all signed consents as they were obtained from a large number of units throughout the hospitals. Hence, rather than having the investigators actively send all signed consents to the trial office, the practice was changed to have the study nurses of the trial office actively collect all consents on a daily basis. However, the number of patients excluded postrandomisation was equally distributed between the two groups. Finally, a small number of patients either did not receive SAP at all or had SAP initiated after surgical incision or had a wound class that was upgraded to category 4 during surgery. Exclusion of these patients from the statistical analysis did not change the findings of this study.

In conclusion, early administration of cefuroxime (plus metronidazole in colorectal surgery) did not significantly lower the risk of SSI compared to late administration before incision. Even though the present results do not rule out a beneficial effect of early administration of SAP on the risk of SSI, they do not support changing current recommendations to administer SAP during the 60 minutes prior to incision. 


\section{Authors' contributions}

Authorship was based according to the ICMJE recommendations on the following 4 criteria:

1. Substantial contributions to the conception or design of the work; or the acquisition, analysis, or interpretation of data for the work; AND

2. Drafting the work or revising it critically for important intellectual content; AND

3. Final approval of the version to be published (once applicable); AND

4. Agreement to be accountable for all aspects of the work in ensuring that questions related to the accuracy or integrity of any part of the work are appropriately investigated and resolved.

The study was designed by Walter P. Weber, Rachel Rosenthal, Marcel Zwahlen and Walter R. Marti.

Walter P. Weber, Edin Mujagic, Marcel Bundi, Henry Hoffmann, Savas D. Soysal, Marko Kraljevic, Tarik Delko, Marco von Strauss, Lukas Iselin, Richard X. Sousa Da Silva, Jasmin Zeindler, Rachel Rosenthal, Heidi Misteli, Christoph Kindler, Peter Müller, Andrea Kopp Lugli, Mark Kaufmann, Lorenz Gürke, Daniel Oertli, Evelin Bucheli-Laffer, Julia Landin, Andreas F. Widmer, Christoph A. Fux, and Walter R. Marti collected the data.

Ramon Saccilotto performed central data review and preparation of the data for statistical analysis.

Ramon Saccilotto and Marcel Zwahlen conducted all statistical analyses.

Walter P. Weber, Edin Mujagic, Marcel Bundi, Henry Hoffmann, Savas D. Soysal, Marko Kraljevic, Tarik Delko, Marco von Strauss, Lukas Iselin, Richard X. Sousa Da Silva, Jasmin Zeindler, Rachel Rosenthal, Heidi Misteli, Christoph Kindler, Peter Müller, Andrea Kopp Lugli, Mark Kaufmann, Lorenz Gürke, Daniel Oertli, Evelin Bucheli-Laffer, Julia Landin, Andreas F. Widmer, Christoph A. Fux, Ramon Saccilotto, Marcel Zwahlen and Walter R. 
Published in final edited form as: Lancet Infect Dis. 2017 Jun;17(6):605-614. doi: 10.1016/S1473-3099(17)30176-7

Marti contributed to the final draft of the manuscript and vouch for the accuracy and completeness of the data. 


\section{Conflict of interest statements}

Dr. Weber reports grants from Swiss National Science Foundation, grants from Hospital of Aarau, grants from University of Basel, grants from Gottfried und Julia Bangerter-Rhyner Foundation, grants from Hippocrate Foundation, grants from Nora van Meeuwen-Häfliger Foundation, during the conduct of the study; and Walter Paul Weber received a research grant from Takeda Pharmaceuticals International for another randomized controlled trial not related to this work and has consulted for Genomic Health in the past.

Dr. Mujagic, Dr. Bundi, Dr. Hoffmann, Dr. Soysal, Dr. Kraljevic, Dr. Delko, Dr. von Strauss, Dr. Iselin, Dr. Sousa Da Silva, Dr. Zeindler, Dr. Misteli, Dr. Kindler, Dr. Müller, Dr. Saccilotto, Dr. Kopp Lugli, Dr. Kaufmann, Dr. Gürke, Dr. Oertli, Dr. Bucheli-Laffer, Dr. Landin, Dr. A. Fux, and Dr. Walter R. Marti report grants from Swiss National Science Foundation, grants from Hospital of Aarau, grants from University of Basel, grants from Gottfried und Julia Bangerter-Rhyner Foundation, grants from Hippocrate Foundation, grants from Nora van Meeuwen-Häfliger Foundation, during the conduct of the study; .

Dr. Zwahlen reports grants from Swiss National Science Foundation, during the conduct of the study; grants from Swiss National Science Foundation (www.snf.ch/), personal fees from World Cancer Research Fund International (www.wcrf.org/), grants from AstraZeneca AG, Switzerland, Aptalis Pharma Inc., Dr. Falk Pharma GmbH, Germany, Glaxo Smith Kline AG, Nestlé S. A., Switzerland, Receptos Inc., Regeneron Inc., personal fees from Board member of Bern Cancer League, from null, outside the submitted work.

Dr. Rosenthal reports grants from Swiss National Science Foundation, grants from Hospital of Aarau, grants from University of Basel, grants from Gottfried und Julia Bangerter-Rhyner Foundation, grants from Hippocrate Foundation, grants from Nora van Meeuwen-Häfliger Foundation, during the conduct of the study; other from F. Hoffmann-La Roche Ltd., outside the submitted work. 
Dr. Widmer reports grants from Swiss National Science Foundation, grants from Commission for Technology and Innovation, grants from University of Basel, during the conduct of the study. 


\section{Acknowledgments}

The authors thank Julia Gutzwiller, Aline Koller, Jennifer Luell, Kawa Yousef, Evi Hoene, Franziska Maeder and Constanze Spelters for their assistance in data collection, Yannick Franc for assisting in conducting the interim analysis and Cornel Kaufmann for programming the software for data capturing and management. 
Figure 1. Trial profile

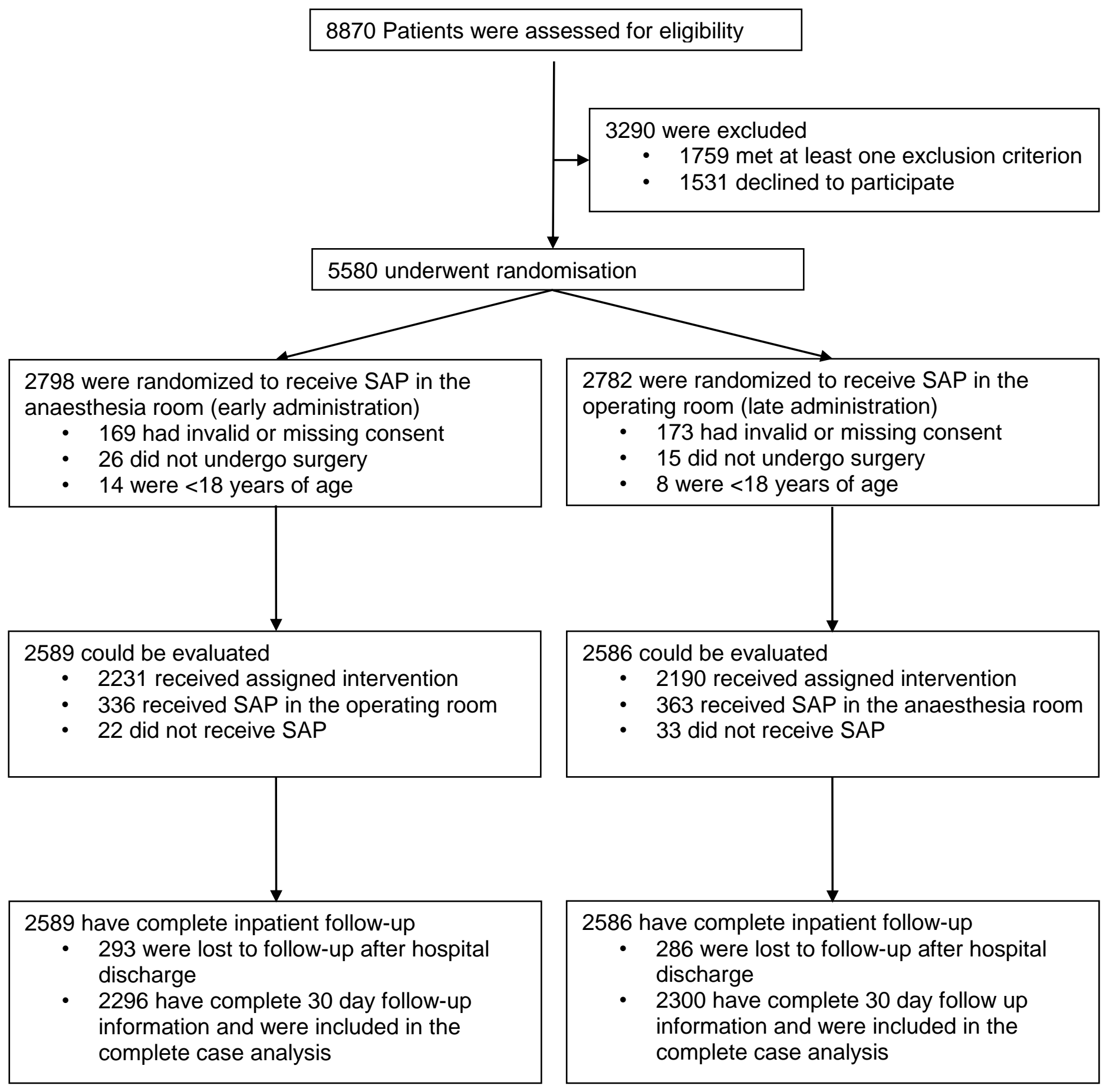


Table 1. Baseline characteristics of the intention-to-treat population.

\begin{tabular}{|c|c|c|c|c|}
\hline \multirow[b]{2}{*}{ Study site } & \multicolumn{2}{|c|}{$\begin{array}{c}\text { SAP+ in anaesthesia room } \\
\text { (early administration) } \\
n=2589\end{array}$} & \multicolumn{2}{|c|}{$\begin{array}{c}\text { SAP+ in operating room } \\
\text { (late administration) } \\
n=2586\end{array}$} \\
\hline & $\begin{array}{c}\text { Basel } \\
n=1502\end{array}$ & $\begin{array}{c}\text { Aarau } \\
n=1087\end{array}$ & $\begin{array}{c}\text { Basel } \\
n=1493\end{array}$ & $\begin{array}{c}\text { Aarau } \\
n=1093\end{array}$ \\
\hline \multirow{2}{*}{$\begin{array}{l}\text { Timing of SAP }{ }^{+} \\
\text {min. before incision }\end{array}$} & \multicolumn{2}{|c|}{$42(30-55)$} & \multicolumn{2}{|c|}{$16(10-25)$} \\
\hline & $40(30-55)$ & $43(32-55)$ & $20(11-30)$ & $14(9-20)$ \\
\hline \multirow{2}{*}{ Unknown } & \multicolumn{2}{|c|}{$22(0.9)$} & \multicolumn{2}{|c|}{$33(1 \cdot 3)$} \\
\hline & $12(0 \cdot 8)$ & $10(0.92)$ & $17(1 \cdot 1)$ & $16(1 \cdot 5)$ \\
\hline \multicolumn{5}{|l|}{ Sex - number (\%) } \\
\hline \multirow{2}{*}{ Male } & \multicolumn{2}{|c|}{$1412(54 \cdot 5)$} & \multicolumn{2}{|c|}{$1390(53 \cdot 8)$} \\
\hline & $782(52 \cdot 1)$ & $630(58 \cdot 0)$ & $777(52 \cdot 0)$ & $613(56 \cdot 1)$ \\
\hline \multirow{2}{*}{ Female } & \multicolumn{2}{|c|}{$1177(45 \cdot 5)$} & \multicolumn{2}{|c|}{$1196(46 \cdot 3)$} \\
\hline & $720(47 \cdot 9)$ & $457(42 \cdot 0)$ & $716(48 \cdot 0)$ & $480(43.9)$ \\
\hline \multirow{2}{*}{ Age - years } & \multicolumn{2}{|c|}{$58.4(43.5-71.9)$} & \multicolumn{2}{|c|}{$59 \cdot 0(42.4-71 \cdot 5)$} \\
\hline & $60 \cdot 2(45 \cdot 1-73 \cdot 9)$ & $56 \cdot 5(42 \cdot 0-69 \cdot 3)$ & $60 \cdot 8(43 \cdot 2-72 \cdot 8)$ & $56 \cdot 1(41 \cdot 1-69 \cdot 5)$ \\
\hline \multicolumn{5}{|l|}{ ASA $\ddagger$ score } \\
\hline \multirow{2}{*}{1} & \multicolumn{2}{|c|}{$455(17 \cdot 6)$} & \multicolumn{2}{|c|}{$477(18 \cdot 5)$} \\
\hline & $228(15 \cdot 2)$ & $227(20 \cdot 9)$ & $236(15 \cdot 8)$ & $241(22 \cdot 1)$ \\
\hline \multirow{2}{*}{2} & \multicolumn{2}{|c|}{$1395(53 \cdot 9)$} & \multicolumn{2}{|c|}{$1339(51 \cdot 8)$} \\
\hline & $807(53 \cdot 7)$ & $588(54 \cdot 1)$ & $770(51 \cdot 6)$ & $569(52 \cdot 1)$ \\
\hline \multirow{2}{*}{3} & \multicolumn{2}{|c|}{$712(27 \cdot 5)$} & & $3 \cdot 5)$ \\
\hline & $447(29 \cdot 8)$ & $265(24.4)$ & $459(30 \cdot 7)$ & $277(25 \cdot 3)$ \\
\hline 4 & & & & \\
\hline 4 & $20(1 \cdot 3)$ & $7(0 \cdot 6)$ & $28(1.9)$ & $6(0.6)$ \\
\hline Surgical division & & & & \\
\hline General & 12 & $8 \cdot 4)$ & 1,2 & $8 \cdot 7)$ \\
\hline & $649(43 \cdot 2)$ & $604(55 \cdot 6)$ & $654(43 \cdot 8)$ & $604(55 \cdot 3)$ \\
\hline Trauma & 10 & $8 \cdot 7)$ & 10 & $8 \cdot 8)$ \\
\hline Irauma & $644(42 \cdot 9)$ & $358(32 \cdot 9)$ & $633(42 \cdot 4)$ & $370(33.9)$ \\
\hline Vaccular & & -9) & & $6)$ \\
\hline vascular & $209(13 \cdot 9)$ & $125(11 \cdot 5)$ & $206(13 \cdot 8)$ & $119(10 \cdot 9)$ \\
\hline Wound class & & & & \\
\hline 1 & 20 & $9 \cdot 0)$ & 20 & $8 \cdot 7)$ \\
\hline 1 & $1306(87 \cdot 0)$ & $739(68 \cdot 0)$ & $1294(86 \cdot 7)$ & $740(67 \cdot 7)$ \\
\hline II & & $5 \cdot 5)$ & & (3) \\
\hline II & $135(9 \cdot 0)$ & $266(24.5)$ & $137(9 \cdot 2)$ & $258(23 \cdot 6)$ \\
\hline$\mu$ & & & & \\
\hline III & $43(2 \cdot 9)$ & $73(6 \cdot 7)$ & $43(2 \cdot 9)$ & $77(7 \cdot 0)$ \\
\hline IV & & & & \\
\hline
\end{tabular}




\begin{tabular}{|c|c|c|c|c|}
\hline & $18(1 \cdot 2)$ & $9(0 \cdot 8)$ & $19(1 \cdot 3)$ & $18(1 \cdot 7)$ \\
\hline \multicolumn{5}{|l|}{ Diabetes } \\
\hline \multirow{2}{*}{ No } & \multicolumn{2}{|c|}{$2337(90 \cdot 3)$} & \multicolumn{2}{|c|}{$2358(91 \cdot 2)$} \\
\hline & $1367(91 \cdot 0)$ & $970(89 \cdot 2)$ & $1478(91 \cdot 2)$ & $996(91 \cdot 1)$ \\
\hline \multirow{2}{*}{ NIDDM† } & \multicolumn{2}{|c|}{$158(6 \cdot 1)$} & \multicolumn{2}{|c|}{$136(5 \cdot 3)$} \\
\hline & $74(4 \cdot 9)$ & $84(7 \cdot 7)$ & $72(4 \cdot 8)$ & $64(5 \cdot 9)$ \\
\hline \multirow{2}{*}{ IDDM†† } & \multicolumn{2}{|c|}{$94(3 \cdot 6)$} & \multicolumn{2}{|c|}{$92(3 \cdot 6)$} \\
\hline & $61(4 \cdot 1)$ & $33(3 \cdot 0)$ & $59(4 \cdot 0)$ & $33(3.0)$ \\
\hline \multicolumn{5}{|c|}{ Immunosuppressive drugs } \\
\hline \multirow{2}{*}{ No } & \multicolumn{2}{|c|}{$2558(98 \cdot 8)$} & \multicolumn{2}{|c|}{2557 (98.9) } \\
\hline & $1488(99 \cdot 1)$ & $1070(98 \cdot 4)$ & $1478(99 \cdot 0)$ & $1079(98 \cdot 7)$ \\
\hline \multirow{2}{*}{ Yes } & \multicolumn{2}{|c|}{$31(1 \cdot 2)$} & \multicolumn{2}{|c|}{$29(1 \cdot 1)$} \\
\hline & $14(0.9)$ & $17(1 \cdot 6)$ & $15(1 \cdot 0)$ & $14(1 \cdot 3)$ \\
\hline \multirow{2}{*}{$B M I^{\star \star}(k g / m 2)$} & \multicolumn{2}{|c|}{$25.7(23.0-29 \cdot 6)$} & \multicolumn{2}{|c|}{$25 \cdot 8(22 \cdot 8-29 \cdot 6)$} \\
\hline & $25 \cdot 3(22 \cdot 6-29 \cdot 1)$ & $26 \cdot 3(23 \cdot 7-30 \cdot 7)$ & $25 \cdot 4(22 \cdot 5-29 \cdot 3)$ & $26 \cdot 3(23 \cdot 2-30 \cdot 1)$ \\
\hline \multirow{2}{*}{ Unknown } & \multicolumn{2}{|c|}{$33(1 \cdot 3)$} & \multicolumn{2}{|c|}{$36(1 \cdot 4)$} \\
\hline & $32(2 \cdot 1)$ & $1(0 \cdot 1)$ & $36(2 \cdot 4)$ & $0(0 \cdot 0)$ \\
\hline \multirow{2}{*}{$\begin{array}{l}\text { Preoperative } \\
\text { albumin (g/l) }\end{array}$} & \multicolumn{2}{|c|}{$37.9(34-40)$} & \multicolumn{2}{|c|}{$37(34.4-40)$} \\
\hline & $37(34-40)$ & $38.6(24.7-41 \cdot 6)$ & $37(34-40)$ & $38.4(35.8-40 \cdot 6)$ \\
\hline \multirow{2}{*}{ Unknown } & \multicolumn{2}{|c|}{$1309(50 \cdot 6)$} & 13 & $9)$ \\
\hline & $422(28 \cdot 1)$ & $887(81 \cdot 6)$ & $435(29 \cdot 1)$ & $880(80.5)$ \\
\hline Preoperative eGFR $^{ \pm}$ & $85 \cdot 8(6$ & $100 \cdot 2)$ & $85.9(\epsilon$ & $100 \cdot 1)$ \\
\hline$(\mathrm{ml} / \mathrm{min} / 1.73 \mathrm{~m} 2)$ & $87 \cdot 8(70 \cdot 4-101 \cdot 6)$ & $79 \cdot 2(63 \cdot 8-96 \cdot 4)$ & $87 \cdot 4(70 \cdot 6-101 \cdot 1)$ & $82.9(61.9-98.4)$ \\
\hline Unknown & 97 & & & -3) \\
\hline 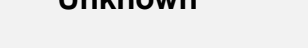 & $416(27 \cdot 7)$ & $557(51 \cdot 2)$ & $428(28 \cdot 7)$ & $536(49 \cdot 0)$ \\
\hline Emergency procedu & & & & \\
\hline Yor & 47 & & & \\
\hline res & $159(10 \cdot 6)$ & $312(28 \cdot 7)$ & $145(9 \cdot 7)$ & $302(27 \cdot 6)$ \\
\hline $\mathrm{No}$ & 211 & 1.8) & 21 & $\cdot 7)$ \\
\hline NO & $1343(89 \cdot 4)$ & $775(71 \cdot 3)$ & $1348(90 \cdot 3)$ & $791(72 \cdot 4)$ \\
\hline Duration of curaery & 90( & 135) & 89 & 135) \\
\hline Durativir oi surgety & $85(57-125)$ & $95(61-155)$ & $85(55-121)$ & $95(62-151)$ \\
\hline Intraoperative redos & & & & \\
\hline Yoc & & & & \\
\hline res & $30(2 \cdot 0)$ & $142(13 \cdot 1)$ & $27(1 \cdot 8)$ & $119(10 \cdot 9)$ \\
\hline No & 241 & $3 \cdot 4)$ & 24 & $4.4)$ \\
\hline 10 & $1472(98 \cdot 0)$ & $945(86 \cdot 9)$ & $1466(98 \cdot 2)$ & $974(89 \cdot 1)$ \\
\hline
\end{tabular}

Percentages may not total 100 due to rounding.

Values are medians with interquartile ranges except where otherwise stated. 
SAP+

ASA

NIDDM†

IDDM+†

$\mathrm{BMI}^{\star *}$

eGFR ${ }^{ \pm}$

Emergency procedurex
Surgical antimicrobial prophylaxis

American Society of Anesthesiologists

Non-insulin dependent diabetes mellitus

Insulin dependent diabetes mellitus

Body-mass index refers to the weight in kilograms divided by the square of the height in metres

Estimated glomerular filtration rate

Non-elective procedures with planned incision $>2$ hours after registration 
Table 2. Effect of early versus late administration of surgical antimicrobial prophylaxis on primary and secondary outcomes in intention-to-treat analysis.

\begin{tabular}{|c|c|c|c|c|}
\hline Outcome & $\begin{array}{l}\text { SAP in } \\
\text { anaesthesia } \\
\text { room (early } \\
\text { administration) } \\
\mathrm{N}=2296 \dagger\end{array}$ & $\begin{array}{l}\text { SAP in } \\
\text { operating room } \\
\text { (late } \\
\text { administration) } \\
N=2300 \dagger\end{array}$ & $\begin{array}{l}\text { Odds ratio } \\
\text { ( } 95 \% \text { confidence } \\
\text { interval) }\end{array}$ & $\mathbf{P}^{*}$ \\
\hline \multicolumn{5}{|l|}{ Primary outcome } \\
\hline Surgical-site infection, n (\%) & $113(4 \cdot 9)$ & $121(5 \cdot 3)$ & $0.93(0.72-1.21)$ & 0.601 \\
\hline Superficial incisional & $48(2 \cdot 1)$ & $55(2 \cdot 4)$ & $0.87(0.59-1.29)$ & 0.491 \\
\hline Deep incisional & $23(1 \cdot 0)$ & $20(0.9)$ & $1.15(0.63-2.11)$ & 0.642 \\
\hline Organ-space & $42(1 \cdot 8)$ & $46(2 \cdot 0)$ & $0.91(0.60-1.39)$ & 0.673 \\
\hline \multicolumn{5}{|l|}{ Secondary outcomes } \\
\hline $\begin{array}{l}\text { All-cause } 30 \text { day mortality, } n \\
\text { (\%) }\end{array}$ & $29(1 \cdot 3)$ & $24(1 \cdot 0)$ & $1 \cdot 21(0.70-2 \cdot 09)$ & 0.485 \\
\hline $\begin{array}{l}\text { Median length of hospital } \\
\text { stay, days (IQR) }\end{array}$ & $5 \cdot 1(3-9)$ & $5 \cdot 0(3-10)$ & $N / A$ & 0.375 \\
\hline
\end{tabular}

* $P$ values for binary outcomes are Wald $p$-values from logistic regression and for length of stay from a Wilcoxon (Mann-Whitney) rank-sum test.

SAP: Surgical antimicrobial prophylaxis

N/A: Not applicable

† These numbers represent the complete case set, i.e. the numbers of cases with complete 30 day follow up. For the secondary outcome "all-cause 30 day mortality", the complete case 
set numbers are 2301 in the early and 2306 in the late group. For the secondary outcome "median length of hospital stay", the complete case set numbers are equal to the total study population, i.e. 2589 for the early and 2586 for the late group. 
Table 3. Spectrum of pathogens in surgical site infections by study site

\begin{tabular}{|c|c|c|c|c|}
\hline \multirow[b]{2}{*}{ Study site } & \multicolumn{2}{|c|}{$\begin{array}{l}\text { SAP+ in anaesthesia room } \\
\text { (early administration) } \\
\mathrm{n}=2296\end{array}$} & \multicolumn{2}{|c|}{$\begin{array}{l}\text { SAP+ in operating room } \\
\text { (late administration) } \\
n=2300\end{array}$} \\
\hline & $\begin{array}{c}\text { Basel } \\
n=1217\end{array}$ & $\begin{array}{c}\text { Aarau } \\
\mathrm{n}=1079\end{array}$ & $\begin{array}{c}\text { Basel } \\
n=1216\end{array}$ & $\begin{array}{c}\text { Aarau } \\
\mathrm{n}=1084\end{array}$ \\
\hline \multirow{2}{*}{ Surgical site infection, $\mathbf{n}(\%)$} & \multicolumn{2}{|c|}{$113(4 \cdot 9)$} & \multicolumn{2}{|c|}{$121(5 \cdot 3)$} \\
\hline & $62(5 \cdot 1)$ & $51(4 \cdot 7)$ & $62(5 \cdot 1)$ & $59(5 \cdot 4)$ \\
\hline \multicolumn{5}{|l|}{ Identification of pathogen } \\
\hline Yes & 13 & 19 & 17 & 24 \\
\hline No & 49 & 32 & 45 & 35 \\
\hline \multicolumn{5}{|l|}{ Pathogens } \\
\hline Escherichia coli & 4 & 7 & 6 & 8 \\
\hline Enterococcus spp. & 3 & 5 & 4 & 7 \\
\hline $\begin{array}{l}\text { Coagulase negative } \\
\text { staphylococci }\end{array}$ & 5 & 1 & 4 & 3 \\
\hline Streptococcus viridans & 2 & 1 & 2 & 5 \\
\hline Staphylococcus aureus & 1 & 3 & 3 & 2 \\
\hline Other enterobacteriaceae & 1 & 2 & 1 & 4 \\
\hline Klebsiella spp. & 1 & 0 & 0 & 5 \\
\hline Pseudomonas aeruginosa & 2 & 1 & 1 & 2 \\
\hline Other anaerobic bacteria & 1 & 2 & 1 & 0 \\
\hline Enterobacter spp. & 0 & 2 & 0 & 1 \\
\hline Bacterioides spp. & 0 & 2 & 0 & 1 \\
\hline Candida albicans & 0 & 2 & 0 & 1 \\
\hline Serratia spp. & 0 & 0 & 0 & 2 \\
\hline Pseudomonas non-aeruginosa & 2 & 0 & 0 & 0 \\
\hline Clostridium spp & 0 & 2 & 0 & 0 \\
\hline Candida spp. & 1 & 1 & 0 & 0 \\
\hline Bacillus spp. & 0 & 1 & 0 & 0 \\
\hline Other gram-positive & 1 & 0 & 0 & 0 \\
\hline Proteus spp. & 0 & 1 & 0 & 0 \\
\hline \multicolumn{5}{|l|}{ Multiresistant pathogens } \\
\hline ESBL† & 1 & 0 & 1 & 2 \\
\hline Others & 0 & 1 & 0 & 2 \\
\hline MRSATt & 0 & 1 & 0 & 0 \\
\hline \multicolumn{5}{|c|}{ SAP+ $\quad$ Surgical Antimicrobial Prophylaxis } \\
\hline \multicolumn{5}{|c|}{ ESBL† $\quad$ Extended Spectrum Beta-Lactamase } \\
\hline \multicolumn{5}{|l|}{ MRSA†† } \\
\hline
\end{tabular}


Figure 2. Subgroup analyses of the effect of early versus late SAP administration on surgical site infection

\section{Figure uploaded as a separate file}

admin.: Administration

BMI: Body mass index

The analyses were performed according to intention-to-treat. Three subgroup analyses were pre-specified: age ( $\geq 65$ versus $<65$ years), body mass index ( $\geq 30$ versus $<30 \mathrm{~kg} / \mathrm{m} 2$ ) and diabetes (with versus without). Three subgroup analyses were post hoc: Surgical division (visceral versus trauma versus vascular), presence versus absence of immunosuppressive drugs and wound class (I versus II versus III versus IV). Estimates for the relative effect of early versus late administration of antibiotic prophylaxis on the risk of surgical site infection in each subgroup are presented as odds ratios with $95 \%$ confidence intervals. Interaction terms were included between randomisation group and the respective subgroups to obtain interaction p-values. 


\section{Reference List}

(1) Weber WP, Zwahlen M, Reck S, Feder-Mengus C, Misteli H, Rosenthal R et al. Economic burden of surgical site infections at a European university hospital. Infect Control Hosp Epidemiol 2008 July;29(7):623-9.

(2) Baum ML, Anish DS, Chalmers TC, Sacks HS, Smith H, Jr., Fagerstrom RM. A survey of clinical trials of antibiotic prophylaxis in colon surgery: evidence against further use of no-treatment controls. N Engl J Med 1981 October 1;305(14):795-9.

(3) Hasselgren PO, Ivarsson L, Risberg B, Seeman T. Effects of prophylactic antibiotics in vascular surgery. A prospective, randomized, double-blind study. Ann Surg 1984 July;200(1):86-92.

(4) Platt R, Zaleznik DF, Hopkins CC, Dellinger EP, Karchmer AW, Bryan CS et al. Perioperative antibiotic prophylaxis for herniorrhaphy and breast surgery. N Engl J Med 1990 January 18;322(3):153-60.

(5) Bratzler DW, Houck PM. Antimicrobial prophylaxis for surgery: an advisory statement from the National Surgical Infection Prevention Project. Clin Infect Dis 2004 June 15;38(12):1706-15.

(6) Burke JF. The effective period of preventive antibiotic action in experimental incisions and dermal lesions. Surgery 1961 July;50:161-8.

(7) Classen DC, Evans RS, Pestotnik SL, Horn SD, Menlove RL, Burke JP. The timing of prophylactic administration of antibiotics and the risk of surgical-wound infection. $\mathrm{N}$ Engl J Med 1992 January 30;326(5):281-6.

(8) Allegranzi B, Zayed B, Bischoff P, Kubilay NZ, de JS, de VF et al. New WHO recommendations on intraoperative and postoperative measures for surgical site infection prevention: an evidence-based global perspective. Lancet Infect Dis 2016 November 1.

(9) Bratzler DW, Dellinger EP, Olsen KM, Perl TM, Auwaerter PG, Bolon MK et al. Clinical practice guidelines for antimicrobial prophylaxis in surgery. Am J Health Syst Pharm 2013 February 1;70(3):195-283. 
(10) Dellinger EP, Gross PA, Barrett TL, Krause PJ, Martone WJ, McGowan JE, Jr. et al. Quality standard for antimicrobial prophylaxis in surgical procedures. Infectious Diseases Society of America. Clin Infect Dis 1994 March;18(3):422-7.

(11) National Institute for Health and Care Excellence. A summary of selected new evidence relevant to NICE clinical guideline 74 "Prevention and treatment of surgical site infection" (2008). Evidence update 43. June 2013. Manchester (http://www.nice.org.uk/guidance/cg74/evidence, accessed 18 December 2016). 2013.

(12) Saxer F, Widmer A, Fehr J, Soka I, Kibatala P, Urassa H et al. Benefit of a single preoperative dose of antibiotics in a sub-saharan district hospital: minimal input, massive impact. Ann Surg 2009 February;249(2):322-6.

(13) Steinberg JP, Braun BI, Hellinger WC, Kusek L, Bozikis MR, Bush AJ et al. Timing of antimicrobial prophylaxis and the risk of surgical site infections: results from the Trial to Reduce Antimicrobial Prophylaxis Errors. Ann Surg 2009 July;250(1):10-6.

(14) van Kasteren ME, Mannien J, Ott A, Kullberg BJ, de Boer AS, Gyssens IC. Antibiotic prophylaxis and the risk of surgical site infections following total hip arthroplasty: timely administration is the most important factor. Clin Infect Dis 2007 April $1 ; 44(7): 921-7$.

(15) Alexander JW, Solomkin JS, Edwards MJ. Updated recommendations for control of surgical site infections. Ann Surg 2011 June;253(6):1082-93.

(16) van Kasteren ME, Gyssens IC, Kullberg BJ, Bruining HA, Stobberingh EE, Goris RJ. [Optimizing antibiotics policy in the Netherlands. V. SWAB guidelines for perioperative antibiotic prophylaxis. Foundation Antibiotics Policy Team]. Ned Tijdschr Geneeskd 2000 October 21;144(43):2049-55.

(17) Galandiuk S, Polk HC, Jr., Jagelman DG, Fazio VW. Re-emphasis of priorities in surgical antibiotic prophylaxis. Surg Gynecol Obstet 1989 September;169(3):219-22.

(18) Weber WP, Marti WR, Zwahlen M, Misteli H, Rosenthal R, Reck S et al. The timing of surgical antimicrobial prophylaxis. Ann Surg 2008 June;247(6):918-26. 
(19) World Health Organization 2016. Global Guidelines for the Prevention of Surgical Site Infection (http://apps.who.int/iris/bitstream/10665/250680/1/9789241549882eng.pdf?ua=1; accessed 22 December 2016). 2016.

(20) Mujagic E, Zwimpfer T, Marti WR, Zwahlen M, Hoffmann H, Kindler C et al. Evaluating the optimal timing of surgical antimicrobial prophylaxis: study protocol for a randomized controlled trial. Trials 2014;15:188.

(21) Mangram AJ, Horan TC, Pearson ML, Silver LC, Jarvis WR. Guideline for prevention of surgical site infection, 1999. Hospital Infection Control Practices Advisory Committee. Infect Control Hosp Epidemiol 1999 April;20(4):250-78.

(22) National Healthcare Safety Network of the Centers for Disease Control and Prevention. Procedure-associated Module, Surgical Site Infection (SSI) Event (https://www.cdc.gov/nhsn/PDFs/pscmanual/9pscssicurrent.pdf, accessed 26 December 2016). 2016.

(23) Cole SR, Hernan MA. Adjusted survival curves with inverse probability weights. Comput Methods Programs Biomed 2004 July;75(1):45-9.

(24) Robins JM, Hernan MA, Brumback B. Marginal structural models and causal inference in epidemiology. Epidemiology 2000 September;11(5):550-60.

(25) Hernan MA, Hernandez-Diaz S. Beyond the intention-to-treat in comparative effectiveness research. Clin Trials 2012 February;9(1):48-55.

(26) Berry SM, Carlin BP, Lee JJ, Muller P. Bayesian Adaptive Methods for Clinical Trials.London/New York: Chapman \& Hall/CRC; 2010.

(27) Anderson DJ, Podgorny K, Berrios-Torres SI, Bratzler DW, Dellinger EP, Greene L et al. Strategies to prevent surgical site infections in acute care hospitals: 2014 update. Infect Control Hosp Epidemiol 2014 June;35(6):605-27.

(28) Hutschala D, Skhirtladze K, Kinstner C, Mayer-Helm B, Muller M, Wolner E et al. In vivo microdialysis to measure antibiotic penetration into soft tissue during cardiac surgery. Ann Thorac Surg 2007 November;84(5):1605-10. 
(29) Misteli H, Widmer AF, Weber WP, Bucher E, Dangel M, Reck S et al. Successful implementation of a window for routine antimicrobial prophylaxis shorter than that of the World Health Organization standard. Infect Control Hosp Epidemiol 2012 September;33(9):912-6.

(30) Dellinger EP. What is the ideal time for administration of antimicrobial prophylaxis for a surgical procedure? Ann Surg 2008 June;247(6):927-8. 


\section{Figure 2}

Subgroup

\section{Anaesthesia room Operating room}

\section{Odds Ratio} Published in final edited form as: (late admin.)
no. of events/total no.

Surgical division

Visceral

Trauma

$68 / 1132$

Vascular

$23 / 862$

$22 / 302$

Wound classification

Class

Class II

$70 / 1799$

$26 / 371$

Class III

$14 / 103$

Class IV

$3 / 23$

Immunosuppressive drugs

Yes

No

$2 / 26$

$111 / 2270$

BMI over $30 \mathrm{~kg} / \mathrm{m} 2$

\begin{tabular}{ccc} 
Yes & $13 / 236$ & $17 / 222$ \\
No & $100 / 2060$ & $104 / 2078$ \\
$\begin{array}{c}\text { Diabetes } \\
\text { Yes }\end{array}$ & \\
No & $18 / 228$ & $17 / 209$ \\
Age $>=65$ & $95 / 2068$ & $104 / 2091$ \\
Yes & & \\
No & $58 / 889$ & $63 / 916$ \\
\hline
\end{tabular}

$87 / 1140$
$16 / 870$
$18 / 290$

$69 / 1786$

$37 / 369$

$10 / 112$

$5 / 33$

$3 / 28$

$118 / 2272$

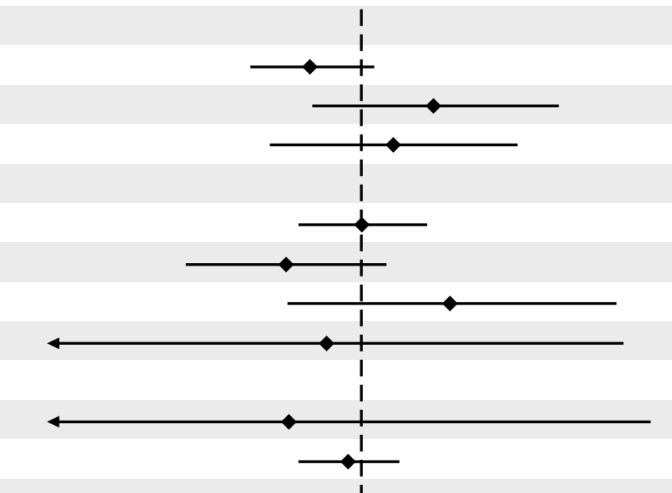

I

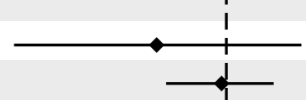

I

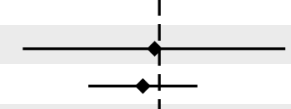

$0.77(0.56-1.07)$

$1.46(0.77-2.79)$

$1 \cdot 19(0.62-2 \cdot 26)$

$1.01(0.72-1.41)$

$0.68(0.40-1 \cdot 14)$

$1.60(0.68-3.79)$

$0.84(0.18-3.93)$

$0.69(0.11-4.53)$

$0.94(0.72-1.22)$

$0.70(0.33-1.48)$

$0.97(0.73-1.28)$

$0.97(0.49-1.93)$

$0.92(0.69-1.22)$

$0.95(0.65-1.37)$

$0.93(0.64-1.36)$

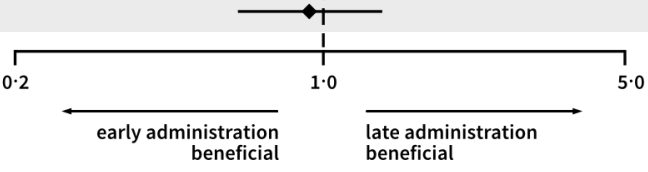

Value for 


\section{Supplementary Material}

\section{Page 2: $\quad$ Supplementary Appendix 1.}

Detailed list of in- and exclusion criteria.

Page 3+4: $\quad$ Supplementary Appendix 2.

Rationale for the use of inverse probability of censoring weights (IPCW).

Page 5: $\quad$ Supplementary Appendix 3.

Risk and $95 \%$ confidence intervals for binary primary and secondary outcomes by randomisation group from IPCW analysis.

\section{Page 6: $\quad$ Supplementary Appendix 4.}

Subgroup analysis of risk of surgical site infection by randomisation group from IPCW analysis.

Page 7: $\quad$ Reference List 


\section{Supplementary Appendix 1.}

\section{Detailed list of in- and exclusion criteria.}

Inclusion criteria:

- Age $\geq 18$ years.

- Inpatient visceral, vascular and trauma procedures.

- SAP indicated according to international guidelines. ${ }^{1}$

Clinical standards for SAP administration are based on CDC guidelines for surgical wound classification, as follows: class I (clean) involving an implant (e.g. hernia mesh repair and trauma surgery), most major vascular and breast surgery procedures; all class II (cleancontaminated) procedures (e.g. colorectal, small intestinal, gastroesophageal, biliary surgery); and class III (contaminated) procedures when the source of infection is surgically entirely removed, obviating the need for antibiotic therapy (e.g. surgery for uncomplicated appendicitis, cholecystitis). CDC class IV (dirty-contaminated) wounds are no indication for SAP. This wound class suggests that the organisms responsible for infection were present in the operative field before surgery. However, since the wound class category is defined during surgery, a small number of procedures $(n=64)$ that received SAP before incision and was later categorized as wound class IV was included in the intention-to-treat analyses.

\section{Exclusion criteria:}

- Contraindication for study drugs.

- Pre-existing antibiotic therapy within 14 days of surgery.

- Any doubt that the patient can make the decision to participate fully informed due to cognitive impairment, such as in critically ill or demented patients.

- Combined operations with other surgical disciplines not participating in this trial

- Indication for SAP other than cefuroxime +/- metronidazole.

- Patients that have already been included in another ongoing interventional study.

- Emergency procedures with planned incision within 2 hours after registration. Emergency procedures within two hours may not allow for proper patient information and randomisation and we wanted to exclude any risk that the procedure could be delayed by the participation in this study. Patients scheduled for less urgent but non-elective procedures with planned incision more than 2 hours after the time of indication were included in this study. 


\section{Supplementary Appendix 2.}

\section{Rationale for the use of inverse probability of censoring weights (IPCW).}

The following table shows a simplified situation with just one dichotomous prognostic factor for SSI. Patients can be separated into a high and a low SSI risk group.

\begin{tabular}{lcccccc}
\hline & $\begin{array}{c}\text { Number of } \\
\text { patients } \\
\text { discharged } \\
\text { from the } \\
\text { hospital }\end{array}$ & $\begin{array}{c}\text { Patients with } \\
\text { available } \\
\text { follow-up } \\
\text { information }\end{array}$ & $\begin{array}{c}\text { Event } \\
\text { recorded at } \\
\text { follow-up }\end{array}$ & $\begin{array}{c}\text { Fraction } \\
\text { with an } \\
\text { event at } \\
\text { follow- } \\
\text { up }\end{array}$ & $\begin{array}{c}\text { Probability } \\
\text { of having } \\
\text { follow-up }\end{array}$ & $\begin{array}{c}\text { Inverse of } \\
\text { the } \\
\text { probability of } \\
\text { having } \\
\text { follow-up } \\
\text { information }\end{array}$ \\
\hline Low-risk & 400 & 360 & 72 & $20 \%$ & $90.0 \%$ & 1.11 \\
High-risk & 600 & 300 & 150 & $50 \%$ & $50.0 \%$ & 2.00 \\
\hline Total & 1000 & 660 & 222 & $34 \%$ & & \\
\hline
\end{tabular}

In the example above, we have 1000 patients discharged from the hospital, and 660 (66\%) could be followed to obtain the follow-up information. However, the availability of follow-up information was not equally distributed among the risk groups. Follow-up information was available in $90 \%$ for the patients in the low-risk group, and in $50 \%$ of the high risk patients. SSI risk among those with available follow-up information was $34 \%$, but $20 \%$ in the low-risk patients and $50 \%$ in the high-risk patients. Therefore, it would be inappropriate to conclude that the SSI risk of $34 \%$ reflects the SSI risk among all 1000 patients.

\section{Obtaining corrected SSI risk estimates}

If we assume that for each risk group the patients with available follow-up information are representative of all the patients of that risk group, we would calculate the SSI risk among all 1000 patients: We expect to have a $20 \%$ risk among all 400 low-risk patients (=80 expected events), and a $50 \%$ risk in high risk patients (=300 expected events). In total we expect 380 events among all 1000 patients, i.e. a SSI risk of $38 \%$.

Mathematically, we would obtain exactly the same result (38\%) if we conducted a weighted analysis restricted to the 660 patients with available follow-up information, but using risk group specific weights which are 1.11 and 2, derived as the inverse of the probability of having follow-up information. This is called Inverse Probability of Censoring Weights (IPWC). There are two advantages of the weighted approach. First, it can easily be extended to more than one prognostic variable for the SSI risk using multivariable logistic regression. Second, in almost all statistical software packages it is possible to perform an analysis in which the units of observation have different statistical weights, and to obtain estimates and $95 \%$ confidence intervals that account for the weighting. However, this presumes that all relevant prognostic variables have been included in the calculation of the weights. If this assumption 
does not hold true, the corrected risk estimate may still be biased which is known as the assumption of "no unmeasured confounding variables". Finally, when using weights as described, one has to be careful how one calculates $95 \%$ confidence intervals for the results. To obtain valid $95 \%$ confidence intervals with $95 \%$ coverage one has to use so-called "robust standard errors" as implemented in many statistical software packages. Another approach will be the use of bootstrap methods. ${ }^{2,3}$ 


\section{Supplementary Appendix 3.}

Risk and $95 \%$ confidence intervals for binary primary and secondary outcomes by randomisation group from IPCW analysis.

\begin{tabular}{|c|c|c|c|c|}
\hline Outcome & $\begin{array}{l}\text { SAP in } \\
\text { anaesthesia } \\
\text { room (early } \\
\text { administration) }\end{array}$ & $\begin{array}{l}\text { SAP in operating } \\
\text { room (late } \\
\text { administration) }\end{array}$ & $\begin{array}{l}\text { Odds ratio } \\
\text { (95 percent } \\
\text { confidence } \\
\text { interval) }\end{array}$ & $\mathbf{p}$ \\
\hline \multicolumn{5}{|l|}{ Primary outcome } \\
\hline Surgical-site infection & $4 \cdot 88(4 \cdot 08-5 \cdot 84)$ & $5 \cdot 22(4 \cdot 39-6 \cdot 21)$ & $0.93(0.72-1.21)$ & 0.598 \\
\hline $\begin{array}{l}\text { Superficial } \\
\text { incisional }\end{array}$ & $2.06(1.55-2.72)$ & $2 \cdot 34(1.80-3 \cdot 04)$ & $0.88(0.59-1.30)$ & 0.507 \\
\hline Deep incisional & $1.00(0.66-1.50)$ & $0.87(0.56-1.35)$ & $1.14(0.63-2.09)$ & 0.660 \\
\hline Organ-space & $1 \cdot 83(1 \cdot 35-2 \cdot 46)$ & $2.01(1.51-2.67)$ & $0.91(0.60-1.39)$ & 0.657 \\
\hline \multicolumn{5}{|l|}{ Secondary outcomes } \\
\hline All-cause 30 day mortality & $1.27(0.88-1.82)$ & $1.04(0.70-1.55)$ & $1 \cdot 22(0.71-2 \cdot 11)$ & 0.471 \\
\hline
\end{tabular}

Values are percentages with 95 percent confidence intervals. There are no absolute numbers shown in this table due to the nature of the inverse probability of censoring weights analysis. 


\section{Supplementary Appendix 4.}

Subgroup analysis of risk of surgical site infection by randomisation group from IPCW analysis.

\section{Figure uploaded as a separate file}




\section{Reference List}

1. Mangram AJ, Horan TC, Pearson ML, Silver LC, Jarvis WR. Guideline for prevention of surgical site infection, 1999. Hospital Infection Control Practices Advisory Committee. Infect Control Hosp Epidemiol 1999;20(4):250-278.

2. Cole SR, Hernan MA. Adjusted survival curves with inverse probability weights.

Comput Methods Programs Biomed 2004;75(1):45-49.

3. Robins JM, Hernan MA, Brumback B. Marginal structural models and causal inference in epidemiology. Epidemiology 2000;11(5):550-560. 


\section{Figure Supplementary Appendix 4}

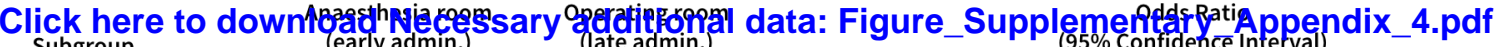

Subgroup

percentage ( $95 \% \mathrm{Cl}$ ) of events per subgroup

Surgical division

$\begin{array}{lll}\text { Visceral } & 6.03(4.78-7.58) & 7.67(6.26-9.37) \\ \text { Trauma } & 2.69(1.79-4.01) & 1.85(1.13-2.99) \\ \text { Vascular } & 7.36(4.89-10.93) & 6.25(3.97-9.71)\end{array}$

Wound classification

$\begin{array}{lcr}\text { Class I } & 3.91(3.11-4.92) & 3.87(3.07-4.88) \\ \text { Class II } & 7.07(4.85-10 \cdot 18) & 10.14(7.43-13.69) \\ \text { Class III } & 13.59(8 \cdot 18-21 \cdot 73) & 9.01(4.89-16.01) \\ \text { Class IV } & 13.04(4.11-34.43) & 15.63(6.47-33.15)\end{array}$

Immunosuppressive drugs

$\begin{array}{llc}\text { Yes } & 7.69(1.84-27 \cdot 00) & 10 \cdot 71(3.37-29 \cdot 25) \\ \text { No } & 4.92(4.10-5 \cdot 89) & 5 \cdot 22(4.37-6.22)\end{array}$

BMI over $30 \mathrm{~kg} / \mathrm{m} 2$

$\begin{array}{ccc}\text { Yes } & 5.53(3.23-9.31) & 7.66(4.80-11.99) \\ \text { No } & 4.90(4.04-5.93) & 5.04(4.17-6.08) \\ \begin{array}{c}\text { Diabetes } \\ \text { Yes }\end{array} & 7.93(5.04-12.25) & 8.21(5.16-12.83) \\ \text { No } & 4.62(3.79-5.62) & 5.00(4.14-6.02) \\ \begin{array}{c}\text { Age > } 65 \\ \text { Yes }\end{array} & 6.61(5.14-8.45) & 6.95(5.47-8.81) \\ \text { No } & 3.92(3.02-5.07) & 4.19(3.26-5.39)\end{array}$

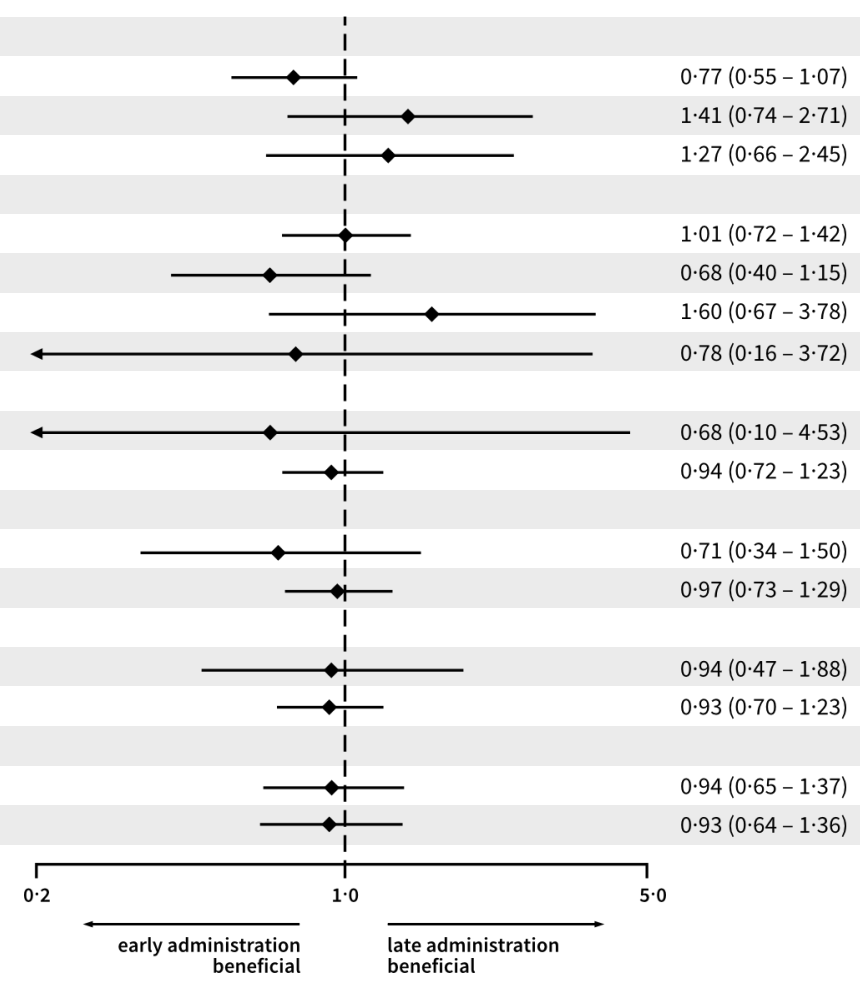




\section{Randomised Controlled Trial to Evaluate the Optimal Timing of Surgical Antimicrobial Prophylaxis}

Principal investigator: W.P. Weber ${ }^{1}$

Co-Investigators: W.R. Marti ${ }^{2}$, E. Mujagic ${ }^{1}$, M. Zwahlen ${ }^{3}$, R. Rosenthal ${ }^{1}$, H. Hoffmann ${ }^{1}$, H. Misteli ${ }^{1}$, Ch. Kindler ${ }^{2}$

Affiliations: $\quad 1$ - University Hospital Basel

2 - Hospital of Aarau

3 - University of Bern

Protocol Date: $\quad$ February 13th, 2012

Amended and submitted for publication February $28^{\text {th }}, 2014$

Published May 24 $4^{\text {th }}, 2014$

Last amended July $30^{\text {th }}, 2015$

All changes to this study protocol that were made after its publication on May $24^{\text {th }}$, 2014 are italicised and explained in parentheses. Those changes are as follows:

Page 9: $\quad$ Definition of primary endpoint

Page 11: $\quad$ Change of originally planned data management software

Page 13: $\quad$ Change to statistical analysis plan

Page 15: $\quad$ Specification of adverse events to be reported

Furthermore, paragraphs that were relevant solely for the purposes of the publishing journal were removed (trial status, competing interests, authors' contributions, authors' information, and acknowledgments). Finally, the entire protocol was revised from American English to British English. 


\section{Background}

\section{The importance of surgical research for the prevention of surgical site infections}

Surgical site infections (SSI) account for $14 \%$ to $16 \%$ of all nosocomial infections in hospitalised patients and are considered the most common form of nosocomial infection among surgical patients [1]. Despite a variety of different prevention measures, as many as $5 \%$ of all patients undergoing surgery develop SSI, which lead to additional morbidity and mortality [2-4]. Patients with SSI require a longer hospital stay, more nursing care, and often readmissions with additional surgery [5-8]. The combined additional direct and indirect costs of treating SSI are substantial [9-12]. Hospitals are under pressure to reduce costs, and efforts to decrease the rate of SSI have therefore become a matter of increasing interest for surgeons, operating room nurses, anaesthesiologists, infection control professionals and healthcare epidemiologists [13]. Nowadays, SSI are considered to reflect the quality of care in a hospital, as they are potentially preventable complications directly linked to surgery. However, many of the current recommendations of the Centers for Disease Control and Prevention (CDC) and the World Health Organization are based on evidence from observational studies in the absence of confirmatory trials $[1,14]$.

\section{Surgical antimicrobial prophylaxis}

The introduction of routine surgical antimicrobial prophylaxis (SAP) was a breakthrough in the prevention of SSI [15]. Today, SAP is administered in surgical units on a daily basis. Based on evidence from observational and randomised controlled trials (RCT), there is widespread agreement for the use of SAP before all gastrointestinal, oropharyngeal and gynaecological procedures [15-23]. There is ongoing controversy about the use of SAP for 'clean' operations, in which the absolute number of infections is low and the number of administrations of SAP needed to prevent one infection is high. It is well accepted for the following clean surgeries, in which the consequence of any infection is severe: orthopaedic prosthesis placement, vascular surgery, open-heart surgery and neurosurgery procedures [24-33]. A reduction in infection rates is well documented for other clean operations such as breast, varicose vein and hernia repair procedures [34-38]. However, in these procedures the morbidity of the infection is generally low and the benefits of SAP must be balanced against its costs and possible adverse effects. 
Several antibiotics have been shown to reduce the incidence of SSI. Many hospitals, especially in the US, use very complex SAP regimes with a variety of antimicrobial drugs that have different pharmacokinetics depending on the type of surgery performed $[15,16,39,40]$. Current guidelines, however, suggest that single-shot administration of a firstor second-generation cephalosporin is sufficient for optimal prevention of SSI in the absence of high rates of resistant bacteria [41]. Due to a limited anaerobic activity of most cephalosporins, treatment is supplemented with metronidazole where indicated. The time interval to motivate redosing is generally set at four hours. Therefore, in several hospitals in Switzerland, including the University Hospital of Basel and the Hospital of Aarau, SAP consists of single-shot administration of cefuroxime (a second-generation cephalosporin), combined with metronidazole in colorectal and proctologic surgery, that is repeated in operations exceeding four hours.

\section{When to administer surgical antimicrobial prophylaxis?}

Before the late 1960s, most prophylactic antibiotics were administered after the end of a surgical procedure and were found to be ineffective [42]. In 1961, Burke [43] showed the timing of SAP to be crucial in animals. Subsequent studies in humans suggested that adequate tissue levels of an appropriate antibiotic during surgery were essential [21,44-47]. The observational landmark study by Classen and colleagues [48] in 1992 provided the basis for the antimicrobial agents to be administered within two hours before skin incision. Other authors narrowed the optimal window for SAP to less than 60 minutes before skin incision $[49,50]$. Importantly, two large prospective studies observed the lowest risk of SSI when SAP was given within 30 minutes prior to incision, and the National Surgical Infection Prevention Project simply recommends administering SAP as close to the incision time as possible [51-53]. Similar statements are made in European guidelines [54,55].

However, despite the obvious importance of infection control by SAP, none of the recommendations on the optimal timing is backed by evidence obtained from a RCT. The historic study by Classen and colleagues [48] was conducted when it was standard practice to administer antibiotics to all patients for at least 24 hours, which was extended to $\geq 48$ hours in more than $80 \%$ of cases. Moreover, the antibiotics administered had widely varying half-life times. Consequently, the Classen et al. time window may not be appropriate for an optimal prevention of SSI as practiced today with single-shot regimes. In addition, there is little evidence in the literature to suggest that tissue levels of cefuroxime could reach the minimum inhibitory concentration within a few minutes after administration. Different authors have attained appropriate tissue levels of cefuroxime anywhere from 20 to 90 minutes after 
intravenous application [56-58]. The translocation of skin microorganisms into the wound during incision is the first vulnerable phase of surgery, and administering SAP only a few minutes before incision might not be optimal to achieve the tissue levels required to prevent SSI.

Several recent studies of other antimicrobial agents with different pharmacokinetics support this hypothesis. In vivo microdialysis, for example, is a new development that allows the measurement of continuous unbound antibiotic concentrations in muscular and subcutaneous interstitial fluid during surgery. Hutschala et al. [59] described this in vivo approach of microdialysis to measure continuous tissue levels of cefazolin. Importantly, the authors state that 'Cefazolin should be administered at least 60 minutes before skin incision to guarantee for optimal tissue concentration at the beginning of surgery. Vast interindividual differences were observed for the time required to reach maximum interstitial concentrations. So it seems reasonable to administer the prophylactic antibiotic as early as possible before skin incision' [59].

Two recent prospective observational studies of other antimicrobial agents with different pharmacokinetics are noteworthy [60,61]. In one, the administration of vancomycin 16 to 60 minutes before incision in coronary artery bypass surgery was associated with the lowest risk of SSI [60]. The other study showed that the rate of SSI after uncomplicated open appendectomy was lower when the antibiotic was administered more than one hour versus one hour or less before surgery [61]. Finally, the results of an observational cohort study performed at the University Hospital of Basel suggest that the ideal timing of SAP is between 74 and 30 minutes before skin incision [62].

\section{Relevant ongoing research}

As of 27 January 2014, there are 198 studies on 'surgical site infection AND prevention' or 'surgical site infection AND prophylaxis' - excluding the present one - registered on ClinicalTrials.gov, 88 of which are open. There were 122 studies found using the terms 'surgical site infection AND antibiotic', all of which were covered by the above search criteria. Finally, there were 75 studies found using 'surgical site infection AND prophylaxis AND antibiotic'.

None of these 198 studies investigates the incidence of SSI as a function of SAP timing. Instead, most of them assess the impact of multiple SSI prevention measures on the risk of SSI, such as nasal decontamination, surgical hand antisepsis, preoperative patients' skin cleansing, hair clipping, supplemental oxygen, local warming and antibacterial sutures. 
Some studies focus on different aspects of SAP, such as the overall efficacy of different types, doses, durations or ways of applications of SAP in specific subsets of patients; others assess the impact of quality improvement programs on compliance with current guidelines.

In summary, SSI are frequent surgical complications that have an important impact on healthcare costs. SAP prevents SSI and has therefore become a main stem of surgical infection control in many surgical interventions. Current guidelines for the correct timing of SAP, however, are still based on observational and pharmacokinetic studies. Such studies have recently achieved discordant results. A well-conducted RCT seems warranted to obtain a clear answer on the optimal timing. There is currently no ongoing or planned trial registered on ClinicalTrials.gov to address this question. The use of a single-shot single-drug SAP regime at two tertiary referral centres in Switzerland provides an ideal setting to plan and conduct an RCT on the optimal timing of SAP.

\section{Current state of own research in the field}

In a quality assessment study conducted at the University Hospital of Basel, we prospectively followed 6,283 consecutive general, oncologic, vascular and orthopaedic trauma surgery procedures closely for evidence of SSI, and then analysed the dataset for the influence of various SSI risk factors. The a priori hypothesis of that study was that the timing of SAP would have a significant impact on the occurrence of SSI. The lowest rates of SSI were observed with the antibiotics being administered between 74 and 30 minutes before surgery, and the association remained virtually unchanged when controlling for patient and procedural risk factors for SSI [62].

Within that cohort study, a matched case-control study was conducted on the economic impact of in-hospital SSI at the University Hospital of Basel. The mean additional hospital cost per SSI was 19,638 CHF (95\% confidence interval 8,492 to 30,784 ) or 12,765 Euro (95\% confidence interval 5,520 to 20,010 ) [63]. Further analyses of this cohort study suggest that glove perforation is associated with an increased SSI risk in the absence of SAP, but show no statistically significant associations between transfusion, anaemia or tutorial assistance and the risk of SSI [64-66]. A review of the microbiological features of SSI in this series demonstrates the absence of multiresistant germs and validates the continuous use of single-shot single-drug SAP with cefuroxime (plus metronidazole in colorectal and proctologic surgery) [67]. Finally, a secondary analysis has been conducted to assess the sensitivity of our clinicians SSI surveillance system to register in-hospital SSI [68]. 


\begin{abstract}
Aims
The final goal of this present project is to reduce the rate of SSI by providing level I evidence on the optimal timing of the administration of SAP in general, oncologic, vascular and orthopaedic trauma surgery. We expect that evidence to influence international guidelines for SAP. The hypothesis to be tested is that the risk of SSI is significantly lower with cefuroxime (plus metronidazole in colorectal surgery) applied in the anaesthesia room (75 to 30 minutes before surgery) as compared to its administration in the operating room (within the final 30 minutes before surgery) [62].
\end{abstract}

\title{
Methods/design
}

\section{Study design and sites}

This bi-centre prospective RCT is being conducted at the University Hospital Basel and the Hospital of Aarau, two tertiary referral centres in Switzerland. The trial has been registered on ClinicalTrials.gov under the identifier NCT01790529.

\section{Patients}

Eligible patients are informed about the study by a member of the surgical team and receive a patient information sheet explaining the rationale and procedures of the study. The information sheet is available in Albanian, English, French, German, Italian, Portuguese, Serbo-Croatian, Spanish and Turkish. Written informed consent is obtained from each patient prior to randomisation (Figure 1) 
Figure 1 Study flow chart

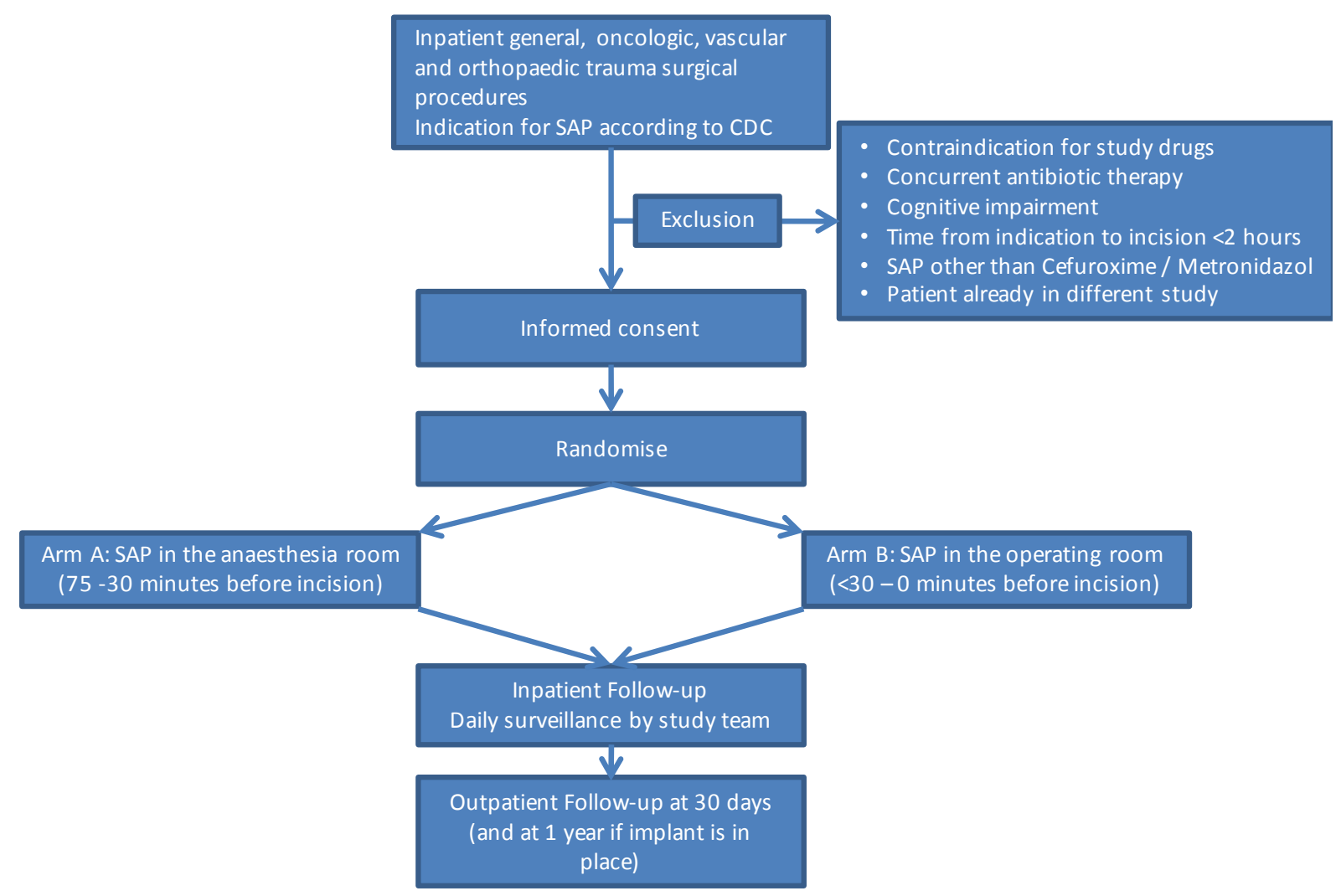

CDC: Centers for Disease Control and Prevention; SAP: surgical antimicrobial prophylaxis.

\section{Inclusion criteria}

Inpatients aged 18 years or older undergoing general, oncologic, vascular and orthopaedic trauma procedures with an indication for SAP according to clinical standards are eligible for this study.

Clinical standards for SAP administration are based on CDC guidelines for surgical wound classification as follows: class I (clean) involving an implant (for example, hernia mesh repair and trauma surgery), and most major vascular and breast surgery procedures; class II (clean-contaminated) procedures (for example, colorectal, small intestinal, gastroesophageal and biliary surgery); and class III (contaminated) procedures when the source of infection is surgically removed, obviating the need for antibiotic therapy (for example, surgery for uncomplicated appendicitis, cholecystitis) [1]. SAP is not indicated for CDC class IV (dirtycontaminated) wounds. This wound class suggests that the organisms causing postoperative infection were present in the operative field before the operation, and patients 
are frequently receiving therapeutic antimicrobial agents perioperatively for established infections. Therefore, neither the term SAP nor the term SSI is correct in such procedures.

\section{Exclusion criteria}

Patients are excluded on the following bases:

- Outpatient surgery

- Contraindication for study drugs, in particular penicillin type I allergy

- Pre-existing antibiotic therapy within 14 days of surgery

- Any doubt that the patient can make the decision to participate fully informed because of cognitive impairment, such as in critically ill patients or those with dementia

- Combined operations between general, oncologic, vascular or orthopaedic trauma surgery and other surgical disciplines not participating in this trial

- Indication for SAP other than cefuroxime and/or metronidazole

- Patients who have already been included in other interventional studies, unless specific permission has been granted in accordance with local ethics committee guidelines

- Emergency procedures with planned incision within two hours after the surgeon indicated the procedure.

In the case of the latter criterion, emergency procedures within two hours may not allow for proper patient information and randomisation and we want to exclude any risk that the procedure could be delayed by participation in this study. Patients scheduled for less urgent but non-elective procedures with planned incision more than two hours after the time of indication are eligible for participation in this study since evidence for the correct timing of SAP in such procedures is needed and cannot simply be deduced from elective procedures. Thus, the results of this trial potentially have an impact on the prevention of SSI in patients undergoing such procedures in the future. However, if obtaining appropriate informed consent is jeopardized by the urgency of the procedure, the patient will be excluded and data on the reason for individual exclusion will be collected.

\section{Randomisation and intervention}

After written informed consent is obtained from eligible patients, they are randomised electronically and stratified by hospital, according to a pre-existing randomisation list. Randomisation results are presented both electronically and printed to the anaesthesiologist 
responsible for SAP administration. Patients are not informed on group assignment. They are randomised in a 1:1 ratio to have SAP administered in the anaesthesia room, which is located next to the actual operating room (arm A), versus in the operating room itself (arm $B)$. Patients in arm A receive the antibiotics between arrival in the anaesthesia room and transfer to the operating room, corresponding to the time window of 75 to 30 minutes before the scheduled incision. Patients in arm B receive the antibiotics between arrival in the operating room and the time of incision, corresponding to the time window of less than 30 minutes to 0 minutes before the scheduled incision. SAP is administered by the anaesthetic team to all patients via single-shot, intravenous infusion of $1.5 \mathrm{~g}$ (or $3 \mathrm{~g}$ for patients $\geq 80 \mathrm{~kg}$ ) of cefuroxime in $100 \mathrm{ml}$ of a $0.9 \%$ sodium chloride solution within 5 minutes and is combined with metronidazole ( $500 \mathrm{mg}$ (or $1,000 \mathrm{mg}$ for patients $\geq 80 \mathrm{~kg}$ ) intravenous infusion, within 5 minutes) in colorectal patients, who receive no additional intraluminal antibiotics. Hence, the duration of the infusion is highly standardised. The anaesthesiologist or anaesthesia nurse who administers SAP records the exact time at which the infusion starts. Until 29 April 2013, corresponding to the inclusion of the first 221 patients, we instead recorded the time that the infusion ended. We had to make this amendment for feasibility reasons after consulting several opinion leaders in the field and the corresponding literature, and confirming that the standard is to report when the infusion starts. In operations that last more than four hours, SAP is re-administered every four hours after the first dose. In patients with impaired renal function, this re-dose will be adapted according to the creatinine clearance.

\section{Study endpoints}

The primary endpoint of this study is the occurrence of any SSI within 30 days after surgery (within one year after implant surgery).

Amendment: During the conduct of the study, the CDC National Healthcare Safety Network (NHSN) announced to abandon the generalised 1 year follow up requirement in case of implant surgery. Instead, the surveillance period required by the new definition of deep incisional and organ/space SSI was shortened to 90 days for procedures involving implants (https://www.cdc.gov/nhsn/PDFs/pscmanual/9pscssicurrent.pdf). In addition, the surveillance period was extended from 30 to 90 days for a variety of procedure types. Some of these procedure types were included in the study and did often not involve implants, namely breast surgery, herniorrhaphy, and peripheral vascular bypass surgery. The follow up period of 30 days, however, was not changed for deep incisional and organ/space SSI for all other procedure types, and for all superficial incisional SSI independent of procedure type. Therefore, we decided on July 30, 2015, to use the 30 day follow up for the primary endpoint 
SSI, since this surveillance period was pre-specified for all procedures in the study, and to abandon the additional follow up one year after surgery in case of implants.

SSI are defined as incisional (either superficial or deep) infection or organ-space infection according to CDC criteria [1]. Superficial incisional SSI involve skin and subcutaneous tissues only, common stitch mini-abscesses are excluded; deep incisional infections involve fascia and muscle; and organ/space infections involve any organ or space other than the incised layer of body wall that was opened or manipulated during surgery.

The operating surgeon and his team perform routine wound surveillance according to clinical standards including diagnosis and treatment of SSI. The physicians of the ward who are in charge of inpatient care are masked to the intervention and are responsible for the assessment of SSI for the purpose of this study, which is continuously cross-checked by supervising members of the blinded wound surveillance team. In addition, inpatients are seen regularly by members of the blinded study team. This ensures appropriate sensitivity to detect in-hospital events. Clinicians are not allowed to overrule study team members in arbitrary situations about diagnosing SSI.

For post-discharge follow-up, trained investigators blinded for treatment allocation contact all patients 30 days after surgery by telephone. The past or present occurrence of SSI is assessed using a standardised questionnaire, and the physician who performed postdischarge clinical follow-up is identified. Whenever ongoing SSI are suspected, patients are investigated in the outpatient clinic of the two involved study centres, clinically relevant microbiological samples are cultured as needed, and the patient receives standard treatment. Whenever the telephone assessment suggests past SSI, primary care physicians are contacted and outpatient charts reviewed to gain additional information for validation of the event as described below.

In case of implant surgery, an additional telephone assessment is performed one year after surgery, covering the mandatory follow-up period of one year as defined by CDC in 1999 [1]. As stated in the amendment above, we decided on July 30,2015, to abandon this additional one year follow up due to a change in definition of SSI.

To ensure appropriate specificity, all cases of SSI are validated by a board certified infectious disease specialist who is blinded for the intervention, based on a comprehensive review of patient history, clinical findings, microbiology results and follow-up data. 
Pre-specified secondary endpoints of this study are all-cause 30-day mortality and length of hospital stay. In addition, we plan to evaluate the SSI-related economic burden in a matched case-control study nested within this RCT.

\section{Patient and procedure characteristics}

The selection of demographics and assessment of patients' health profiles are in accordance with the design used in our observational study [62], including all relevant patient characteristics, as well as preoperative laboratory values and factors that might influence wound healing. These involve, but are not limited to, American Society of Anesthesiologists (ASA) score, number of comorbidities on admission, smoking status, diabetes mellitus, immunosuppressive drugs, body mass index, preoperative albumin, wound class, type and duration of surgery, experience of the surgical team, surgical specialty, intraoperative core temperature, adherence to aseptic technique, and emergency procedure. The Study on the Efficacy of Nosocomial Infection Control and the National Nosocomial Infections Surveillance System (NNIS) SSI risk indices are based on some of these variables and will be calculated for each patient.

\section{Study management and administration}

Data management and monitoring is supported by the Clinical Trial Unit of the University Hospital Basel. Source data of every study participant are entered into an electronic data capturing system (eOPPS/ISOP; ProtecData AG, Boswil, Switzerland) and secondarily transferred into the study data management system SecuTrial® (interActive Systems GmbH, Berlin, Germany).

Amendment: Instead of using SecuTrial@, all software for data capturing and management was specifically programmed for the purposes of this study by ProtecData AG, Boswil, Switzerland. The system was programmed in compliance with Good Clinical Practice and fulfilled the criteria of a study database, such as patient data security, limited access, masking of the study team, audit trails, and time/date stamps.

\section{Quality control measures}

\section{Monitoring}

Continuous central and on-site monitoring of the study is performed by an independent committee of the Clinical Trial Unit for quality control and assurance purposes; to evaluate 
the progress of the study; to verify the accuracy and completeness of case report forms (CRFs); to ensure that all protocol requirements are met, and all applicable local authority regulations and investigator's obligations are being fulfilled; and to resolve any inconsistency in the study records. Monitoring will consist of one initiation visit (12 hours), two monitoring visits (two days each) per year and one close-out visit (12 hours) each per centre.

\section{Sample size considerations and statistical analyses}

\section{Sample size consideration}

We base our sample size consideration on the planned 1:1 ratio between the two groups of patients (SAP administered 75 to 30 minutes (arm A) versus less than 30 minutes to 0 minutes (arm B) before surgery), according to the results of our observational study conducted in the years 2000 to 2001 at the University Hospital of Basel [62]. In this study, an average SSI rate of $4.7 \%$ in 3,836 general, oncologic, vascular and orthopaedic trauma surgery procedures was observed. This rate varied between $4.7 \%$ and $6.8 \%$ with SAP given between 29 and 0 minutes before incision, and between $2.4 \%$ and $3.4 \%$ with SAP given 75 to 30 minutes prior to incision. The main scenario for sample size calculations was that administration of SAP 75 to 30 minutes before surgery (in the anaesthesia room) would result in a $33 \%$ relative reduction of SSI risk and that SAP administration less than 30 minutes before surgery (in the operating room) would result in a SSI rate of $5 \%$. We therefore plan to randomise 5,000 patients in a 1:1 ratio, thus resulting in two groups of 2,500 patients each. Sample size calculations were conducted using the 'sampsi' command of Stata Software Version 11 with a power of $80 \%$ and a two-sided type I error of $5 \%$.

\section{Statistical analyses}

In order to analyse the difference in SSI occurrence between the two timing groups, logistic regression models will be used with the treatment group as the main exposure variable. The main analysis will be an intention-to-treat analysis. In secondary analyses, the logistic regression model will include the following known and suspected baseline risk factors for SSI: Wound classification, ASA score, NNIS score, age, body mass index categories, presence of diabetes, smoking status, adherence to aseptic technique, and experience of the surgical team.

Additional analyses of the study will assess whether the difference of SSI risk in the two timing groups differ in specific subsets of patients: age ( $\geq 65$ versus $<65$ years), body mass index ( $\geq 30$ versus $<30 \mathrm{~kg} / \mathrm{m}^{2}$ ), diabetes (with versus without), and previous or current 
smoker (yes versus no). The rationale for these analyses is that we suspect the pharmacokinetics of the study drugs to be different in these subgroups. This might have an impact on the efficacy of SAP in the relevant timing categories.

Descriptive analyses will show the difference in the distribution of exact timing by randomisation group and further analyses will focus on the detailed association of the exact timing of SAP with SSI risk. These latter analyses will be of observational character.

Amendment: The following addition to the statistical analysis plan was done on May 23, 2016: Even though all patients were completely followed during their hospital stays, not all patients could be contacted after discharge to ascertain SSI and vital status at day 30. Therefore, it was decided to not only perform the main intention-to-treat (ITT) analysis with available 30 day SSI and vital status in form of a complete case analysis. The ITT analysis will also be performed using inverse probability of censoring weights (IPCW). [69,70] IPCW analysis accounts for the possibility that the likelihood of having obtained follow-up information might vary and might depend on known risk factors of SSI and mortality. IPCW will be derived from a logistic regression with availability of follow-up information as the outcome including predictors related to surgery (wound class, surgical division, duration of surgery, emergency surgery) and related to the patient (ASA score, number of comorbidities, having diabetes, BMI above 30, being older than 65, taking immunosuppressive drugs and smoking status). Robust standard errors will be used in the IPCW logistic regression analyses.

\section{Interim analysis}

One interim analysis is planned after 2,500 patients. For this interim analysis, the outcome will be 30-day SSI risk. Decisions to stop will be taken using a fully probabilistic approach [71]. Briefly, we will calculate the predictive probability to obtain a statistically significant difference between the two arms at the end of the study. If this predictive probability is less than $5 \%$, we will stop the trial for futility. For illustration, this will occur if the observed risk ratio in the interim analysis (SAP in anaesthesia room versus SAP in operating room) is exactly 1 with $100 \mathrm{SSI}$ in both study arms with 1,250 patients per arm. After 2,500 patients, this would result in an estimate of the risk ratio of 1 with a $95 \%$ confidence interval from 0.77 to 1.31 . The predictive probability to obtain a statistically significant difference $(P<0.05)$ between the two arms is $4.6 \%$ at the end of the study (that is, after the next 2,500 patients in both arms) and thus the trial would be stopped for futility. If the predictive probability to obtain a $P$-value of less than $4.5 \%$ at the end of the study is more (or equal) than $95 \%$, we will stop the trial early for benefit. If not stopped early for superiority, the study continues to 
full length and a $P$-value of less than $4.5 \%$ is necessary to call a final result statistically significant. The overall type I error for this superiority stopping rule is $4.9 \%$ and was estimated using simulations of the scenario of identical SSI risk in two study arms of $5 \%$.

\section{Ethical considerations}

Participation in this trial is strictly voluntary, and patients are allowed to exit the trial at any point without explanation. All eligible patients are provided an information sheet describing the study with sufficient information for them to make an informed decision about their participation in this study. Patients will be excluded if receipt of adequate informed consent is jeopardized by cognitive impairment or the urgency of the procedure.

The study protocol, patients' information sheets and informed consents and their translations were approved by the two respective local ethics committees ('Ethikkommission beider Basel' and 'Kantonale Ethikkommission Kanton Aargau'). Moreover, insurance coverage of general liability has been obtained by both study centres.

Patients who decline to participate in this study are treated according to clinical standards. This includes the administration of SAP in one of the two timing categories. However, these patients will not be included and no study-specific follow-up will be performed.

\section{Participants' confidentiality}

The participants' confidentiality is maintained at all times. For confidentiality reasons, CRFs must not contain any personal data of study participants. Personnel from the sponsor and regulatory authorities and members of the ethics committees are obliged to respect confidentiality and to refrain from divulging the participants' identity or any other personal information they might be aware of. Source data in the hospital's electronic patient information systems are secured by personal passwords and handled with respect to medical secrecy.

\section{Archiving and data retention}

The investigator will maintain all study-related records, such as CRFs, medical records, laboratory reports, informed consent documents, safety reports, information regarding participants who discontinued, and other pertinent data. All records are to be retained by the investigator as long as required by the applicable laws and regulatory requirements (10 years). Thereafter, all data will be destroyed. 
The only parameters exclusively acquired for study purposes are the result of randomisation and whether the 30-day follow-up (one year if an implant is in situ) has been performed or not. As stated in the amendment above, we decided on July 30,2015, to abandon this additional one year follow up due to a change in definition of SSI.

The study is conducted in compliance with this protocol and according to Good Clinical Practice standards as well as legal regulations.

Amendment: However, in accordance with the local ethics committees, only serious adverse events (SAE) are to be reported to the sponsor, specifically death from any cause, life threatening SAE, SAE that cause a prolongation of the length of hospital stay, SAE that cause a persistent and significant handicap to the patient (e.g. stroke) and SAE that necessitate an intervention in order to prevent one or several of the above mentioned. Deaths are additionally reported to the ethics committee within 7 days of becoming apparent to the study team. SSI as SAE are not to be reported as these equal the endpoint of this study. (Because of the high numbers of critically ill patients in the study population and because the surgical antimicrobial prophylaxis is administered per clinical standards, it would be merely impossible to report all adverse events to the sponsor and authorities. This was confirmed by the ethics committees.)

\section{Abbreviations}

ASA, American Society of Anesthesiologists; CDC, Centers for Disease Control and Prevention; CRF, case report form; NNIS, National Nosocomial Infections Surveillance System; RCT, randomised controlled trial; SAP, surgical antimicrobial prophylaxis; SSI, surgical site infection. 


\section{References}

1. Mangram AJ, Horan TC, Pearson ML, Silver LC, Jarvis WR: Guideline for prevention of surgical site infection, 1999. Hospital Infection Control Practices Advisory Committee. Infect Control Hosp Epidemiol 1999, 20:250-278. quiz 279-280.

2. Coello R, Charlett A, Wilson J, Ward V, Pearson A, Borriello P: Adverse impact of surgical site infections in English hospitals. J Hosp Infect 2005, 60(2):93-103.

3. Coskun D, Aytac J, Aydinli A, Bayer A: Mortality rate, length of stay and extra cost of sternal surgical site infections following coronary artery bypass grafting in a private medical centre in Turkey. J Hosp Infect 2005, 60(2):176-179.

4. Kirkland KB, Briggs JP, Trivette SL, Wilkinson WE, Sexton DJ: The impact of surgical-site infections in the 1990s: attributable mortality, excess length of hospitalization, and extra costs. Infect Control Hosp Epidemiol 1999, 20(11):725-730.

5. Jenney AW, Harrington GA, Russo PL, Spelman DW: Cost of surgical site infections following coronary artery bypass surgery. ANZ J Surg 2001, 71(11):662-664.

6. McGarry SA, Engemann JJ, Schmader K, Sexton DJ, Kaye KS: Surgical-site infection due to Staphylococcus aureus among elderly patients: mortality, duration of hospitalization, and cost. Infect Control Hosp Epidemiol 2004, 25(6):461-467.

7. Ortona L, Federico G, Fantoni M, Pallavicini F, Ricci F, Antinori A: A study on the incidence of postoperative infections and surgical sepsis in a university hospital. Infect Control 1987, 8(8):320-324.

8. Vegas AA, Jodra VM, Garcia ML: Nosocomial infection in surgery wards: a controlled study of increased duration of hospital stays and direct cost of hospitalization. Eur $J$ Epidemiol 1993, 9(5):504-510.

9. Engemann JJ, Carmeli Y, Cosgrove SE, Fowler VG, Bronstein MZ, Trivette SL, Briggs JP, Sexton DJ, Kaye KS: Adverse clinical and economic outcomes attributable to methicillin resistance among patients with Staphylococcus aureus surgical site infection. Clin Infect Dis 2003, 36(5):592-598.

10. Hollenbeak CS, Murphy DM, Koenig S, Woodward RS, Dunagan WC, Fraser VJ: The clinical and economic impact of deep chest surgical site infections following coronary artery bypass graft surgery. Chest 2000, 118(2):397-402.

11. Poulsen KB, Bremmelgaard A, Sorensen Al, Raahave D, Petersen JV: Estimated costs of postoperative wound infections. A case-control study of marginal hospital and social security costs. Epidemiol Infect 1994, 113(2):283-295.

12. Whitehouse JD, Friedman ND, Kirkland KB, Richardson WJ, Sexton DJ: The impact of surgical-site infections following orthopedic surgery at a community hospital and a university hospital: adverse quality of life, excess length of stay, and extra cost. Infect Control Hosp Epidemiol 2002, 23(4):183-189.

13. Yasunaga $\mathrm{H}$, Ide $\mathrm{H}$, Imamura $\mathrm{T}$, Ohe $\mathrm{K}$ : Accuracy of economic studies on surgical site infection. J Hosp Infect 2007, 65(2):102-107. 
14. World Health Organization: Objective 6: The team will consistently use methods known to minimize the risk for surgical site infection. In Safe Surgery Saves Lives: WHO Guidelines for Safe Surgery 2009. Geneva: WHO; 2009.

15. Dellinger EP, Gross PA, Barrett TL, Krause PJ, Martone WJ, McGowan JE Jr, Sweet RL, Wenzel RP: Quality standard for antimicrobial prophylaxis in surgical procedures. Infectious Diseases Society of America. Clin Infect Dis 1994, 18(3):422-427.

16. Page CP, Bohnen JM, Fletcher JR, McManus AT, Solomkin JS, Wittmann DH: Antimicrobial prophylaxis for surgical wounds. Guidelines for clinical care. Arch Surg 1993, 128(1):79-88.

17. Clarke JS, Condon RE, Bartlett JG, Gorbach SL, Nichols RL, Ochi S: Preoperative oral antibiotics reduce septic complications of colon operations: results of prospective, randomized, double-blind clinical study. Ann Surg 1977, 186(3):251-259.

18. Nygaard K, Hognestad J: Infection prophylaxis with doxycycline in colorectal surgery. A preliminary report. Scand J Gastroenterol Suppl 1980, 59:37-39.

19. Baum ML, Anish DS, Chalmers TC, Sacks HS, Smith H Jr, Fagerstrom RM: A survey of clinical trials of antibiotic prophylaxis in colon surgery: evidence against further use of notreatment controls. N Engl J Med 1981, 305(14):795-799.

20. Stone HH, Haney BB, Kolb LD, Geheber CE, Hooper CA: Prophylactic and preventive antibiotic therapy: timing, duration and economics. Ann Surg 1979, 189(6):691-699.

21. Polk HC Jr, Lopez-Mayor JF: Postoperative wound infection: a prospective study of determinant factors and prevention. Surgery 1969, 66(1):97-103.

22. Pories WJ, Van Rij AM, Burlingham BT, Fulghum RS, Meelheim D: Prophylactic cefazolin in gastric bypass surgery. Surgery 1981, 90(2):426-432.

23. Chodak GW, Plaut ME: Use of systemic antibiotics for prophylaxis in surgery: a critical review. Arch Surg 1977, 112(3):326-334.

24. Kaiser AB, Clayson KR, Mulherin JL Jr, Roach AC, Allen TR, Edwards WH, Dale WA: Antibiotic prophylaxis in vascular surgery. Ann Surg 1978, 188(3):283-289.

25. Hasselgren $P O$, Ivarsson L, Risberg B, Seeman T: Effects of prophylactic antibiotics in vascular surgery. A prospective, randomized, double-blind study. Ann Surg 1984, 200(1):8692.

26. Fong IW, Baker CB, McKee DC: The value of prophylactic antibiotics in aorta-coronary bypass operations: a double-blind randomized trial. J Thorac Cardiovasc Surg 1979, 78(6):908-913.

27. Austin TW, Coles JC, Burnett R, Goldbach M: Aortocoronary bypass procedures and sternotomy infections: a study of antistaphylococcal prophylaxis. Can J Surg 1980, 23(5):483-485.

28. Geraghty J, Feely M: Antibiotic prophylaxis in neurosurgery. A randomized controlled trial. J Neurosurg 1984, 60(4):724-726. 
29. Barker FG 2nd: Efficacy of prophylactic antibiotic therapy in spinal surgery: a metaanalysis. Neurosurgery 2002, 51(2):391-400. discussion 400-401.

30. Lidwell OM, Lowbury EJ, Whyte W, Blowers R, Stanley SJ, Lowe D: Infection and sepsis after operations for total hip or knee-joint replacement: influence of ultraclean air, prophylactic antibiotics and other factors. J Hyg (Lond) 1984, 93(3):505-529.

31. Bullock R, Van Dellen JR, Ketelbey W, Reinach SG: A double-blind placebo-controlled trial of perioperative prophylactic antibiotics for elective neurosurgery. J Neurosurg 1988, 69(5):687-691.

32. Shapiro M, Wald U, Simchen E, Pomeranz S, Zagzag D, Michowiz SD, Samuel-Cahn E, Wax Y, Shuval R, Kahane Y: Randomized clinical trial of intra-operative antimicrobial prophylaxis of infection after neurosurgical procedures. J Hosp Infect 1986, 8(3):283-295.

33. Young RF, Lawner PM: Perioperative antibiotic prophylaxis for prevention of postoperative neurosurgical infections. A randomized clinical trial. J Neurosurg 1987, 66(5):701-705.

34. Platt R, Zucker JR, Zaleznik DF, Hopkins CC, Dellinger EP, Karchmer AW, Bryan CS, Burke JF, Wikler MA, Marino SK: Perioperative antibiotic prophylaxis and wound infection following breast surgery. J Antimicrob Chemother 1993, 31:43-48.

35. Platt R, Zucker JR, Zaleznik DF, Hopkins CC, Dellinger EP, Karchmer AW, Bryan CS, Burke JF, Wikler MA, Marino SK: Prophylaxis against wound infection following herniorrhaphy or breast surgery. J Infect Dis 1992, 166(3):556-560.

36. Platt R, Zaleznik DF, Hopkins CC, Dellinger EP, Karchmer AW, Bryan CS, Burke JF, Wikler MA, Marino SK, Holbrook KF: Perioperative antibiotic prophylaxis for herniorrhaphy and breast surgery. N Engl J Med 1990, 322(3):153-160.

37. Lewis RT, Weigand FM, Mamazza J, Lloyd-Smith W, Tataryn D: Should antibiotic prophylaxis be used routinely in clean surgical procedures: a tentative yes. Surgery 1995, 118(4):742-746. discussion 746-747.

38. Yerdel MA, Akin EB, Dolalan S, Turkcapar AG, Pehlivan M, Gecim IE, Kuterdem E: Effect of single-dose prophylactic ampicillin and sulbactam on wound infection after tensionfree inguinal hernia repair with polypropylene mesh: the randomized, double-blind, prospective trial. Ann Surg 2001, 233(1):26-33.

39. ABX Guide. http://www.hopkins-abxguide.org.

40. Antimicrobial prophylaxis in surgery. Med Lett Drugs Ther 1997, 39:97-101.

41. Bratzler DW, Houck PM: Antimicrobial prophylaxis for surgery: an advisory statement from the National Surgical Infection Prevention Project. Clin Infect Dis 2004, 38(12):17061715.

42. McKittrick LS, Wheelock FC Jr: The routine use of antibiotics in elective abdominal surgery. Surg Gynecol Obstet 1954, 99(3):376-377.

43. Burke JF: The effective period of preventive antibiotic action in experimental incisions and dermal lesions. Surgery 1961, 50:161-168. 
44. Stone $\mathrm{HH}$, Hooper CA, Kolb LD, Geheber CE, Dawkins EJ: Antibiotic prophylaxis in gastric, biliary and colonic surgery. Ann Surg 1976, 184(4):443-452.

45. DiPiro JT, Vallner JJ, Bowden TA Jr, Clark BA, Sisley JF: Intraoperative serum and tissue activity of cefazolin and cefoxitin. Arch Surg 1985, 120(7):829-832.

46. Friedman RJ, Friedrich LV, White RL, Kays MB, Brundage DM, Graham J: Antibiotic prophylaxis and tourniquet inflation in total knee arthroplasty. Clin Orthop Relat Res 1990, 260:17-23.

47. Martin C, Ragni J, Lokiec F, Guillen JC, Auge A, Pecking M, Gouin F: Pharmacokinetics and tissue penetration of a single dose of ceftriaxone (1,000 milligrams intravenously) for antibiotic prophylaxis in thoracic surgery. Antimicrob Agents Chemother 1992, 36(12):28042807.

48. Classen DC, Evans RS, Pestotnik SL, Horn SD, Menlove RL, Burke JP: The timing of prophylactic administration of antibiotics and the risk of surgical-wound infection. $N$ Engl $J$ Med 1992, 326(5):281-286.

49. Geroulanos S, Marathias K, Kriaras J, Kadas B: Cephalosporins in surgical prophylaxis. J Chemother 2001, 1:23-26.

50. Vuorisalo S, Haukipuro K, Pokela R, Syrjälä H: Risk features for surgical-site infections in coronary artery bypass surgery. Infect Control Hosp Epidemiol 1998, 19(4):240-247.

51. National Nosocomial Infections Surveillance (NNIS): System report, data summary from January 1992 through June 2004, issued October 2004. Am J Infect Control 2004, 32(8):470-485.

52. Steinberg JP, Braun BI, Hellinger WC, Kusek L, Bozikis MR, Bush AJ, Dellinger EP, Burke JP, Simmons B, Kritchevsky SB, Trial to Reduce Antimicrobial Prophylaxis Errors (TRAPE) Study Group: Timing of antimicrobial prophylaxis and the risk of surgical site infections: results from the Trial to Reduce Antimicrobial Prophylaxis Errors. Ann Surg 2009, 250(1):10-16.

53. Van Kasteren ME, Mannien J, Ott A, Kullberg BJ, de Boer AS, Gyssens IC: Antibiotic prophylaxis and the risk of surgical site infections following total hip arthroplasty: timely administration is the most important factor. Clin Infect Dis 2007, 44(7):921-927.

54. Vogel $F$, Naber KG, Wacha H, Shah P: Parenterale Antibiotika bei Erwachsenen. Chemother J 1999, 8:3-49.

55. Kujath P, Bouchard R, Scheele J, Esnaashari $\mathrm{H}$ : Neues in der perioperativen antibiotischen Prophylaxe. Chirurg 2006, 77:490-498.

56. Davies AJ, Lockley RM, Jones A, el-Safty M, Clothier JC: Comparative pharmacokinetics of cefamandole, cefuroxime and cephradine during total hip replacement. $J$ Antimicrob Chemother 1986, 17(5):637-640.

57. Maier W, Strutz J: Concentration of cephalosporins in tissues of the head and neck after parenteral infusion. Chemotherapy 1995, 41(6):421-426. 
58. Alfter G, Schwenzer N, Friess D, Möhrle E: Perioperative antibiotic prophylaxis with cefuroxime in oral-maxillofacial surgical procedures. J Craniomaxillofac Surg 1995, 23(1):38-41.

59. Hutschala D, Skhirtladze K, Kinstner C, Mayer-Helm B, Müller M, Wolner E, Tschernko EM: In vivo microdialysis to measure antibiotic penetration into soft tissue during cardiac surgery. Ann Thorac Surg 2007, 84(5):1605-1610.

60. Garey KW, Dao T, Chen H, Amrutkar P, Kumar N, Reiter M, Gentry LO: Timing of vancomycin prophylaxis for cardiac surgery patients and the risk of surgical site infections. $J$ Antimicrob Chemother 2006, 58(3):645-650.

61. Kasatpibal N, Norgaard M, Sorensen HT, Schønheyder HC, Jamulitrat S, Chongsuvivatwong V: Risk of surgical site infection and efficacy of antibiotic prophylaxis: a cohort study of appendectomy patients in Thailand. BMC Infect Dis 2006, 6:111.

62. Weber WP, Marti WR, Zwahlen M, Misteli H, Rosenthal R, Reck S, Fueglistaler P, Bolli M, Trampuz A, Oertli D, Widmer AF: The timing of surgical antimicrobial prophylaxis. Ann Surg 2008, 247(6):918-926.

63. Weber WP, Zwahlen M, Reck S, Feder-Mengus $\mathrm{C}$, Misteli $\mathrm{H}$, Rosenthal $\mathrm{R}$, Brandenberger D, Oertli D, Widmer AF, Marti WR: Economic burden of surgical site infections at a European university hospital. Infect Control Hosp Epidemiol 2008, 29(7):623629.

64. Misteli H, Weber WP, Reck S, Rosenthal R, Zwahlen M, Fueglistaler P, Bolli MK, Oertli D, Widmer AF, Marti WR: Surgical glove perforation and the risk of surgical site infection. Arch Surg 2009, 144(6):553-558. discussion 558.

65. Rosenthal R, Weber WP, Zwahlen M, Misteli H, Reck S, Oertli D, Widmer AF, Marti WR: Impact of surgical training on incidence of surgical site infection. World J Surg 2009, 33(6):1165-1173.

66. Weber WP, Zwahlen M, Reck S, Misteli H, Rosenthal R, Buser AS, Kaufmann M, Oertli D, Widmer AF, Marti WR: The association of preoperative anemia and perioperative allogeneic blood transfusion with the risk of surgical site infection. Transfusion 2009, 49(9):1964-1970.

67. Misteli H, Widmer AF, Rosenthal R, Oertli D, Marti WR, Weber WP: Spectrum of pathogens in surgical site infections at a Swiss university hospital. Swiss Med Wkly 2011, 140:w13146.

68. Rosenthal R, Weber WP, Marti WR, Misteli H, Reck S, Dangel M, Oertli D, Widmer AF: Surveillance of surgical site infections by surgeons: biased underreporting or useful epidemiological data? J Hosp Infect 2010, 75(3):178-182.

69. Cole SR, Hernan MA: Adjusted survival curves with inverse probability weights. Computer methods and programs in biomedicine 2004, 75(1):45-49.

70. Robins JM, Hernan MA, Brumback B. Marginal structural models and causal inference in epidemiology. Epidemiology 2000 September;11(5):550-60. 
71. Berry SM, Carlin BP, Lee JJ, Muller P: Bayesian Adaptive Methods for Clinical Trials. Boca Raton, FL: Chapman \& Hall/CRC Biostatistics Series; 2010. 